\title{
DOE/OR/00033--T756 AHP
}

AN APPLICATION OF BROOKHAVEN NATIONAL LABORATORY'S HOT PARTICLE METHODOLOGY FOR DETERMINING THE MOST EFFECTIVE BETA PARTICLE ENERGY IN CAUSING SKIN ULCERS.
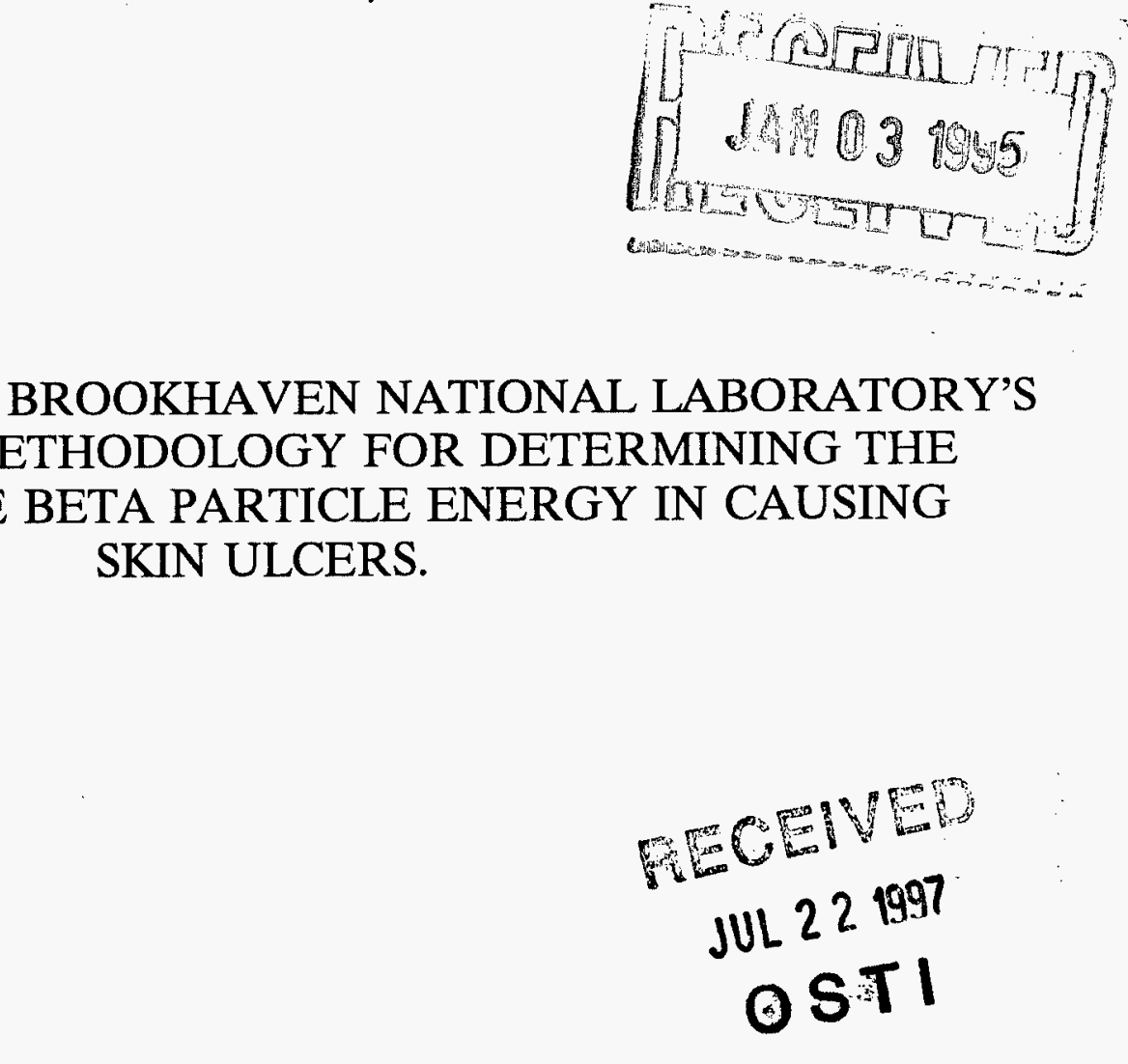

BY

CHARLES SCHAEFER

NOVEMBER, 1994

A GRADUATE PROJECT IN PARTIAL FULFILLMENT OF THE REQUIREMENTS FOR THE DEGREE OF MASTER OF SCIENCE.

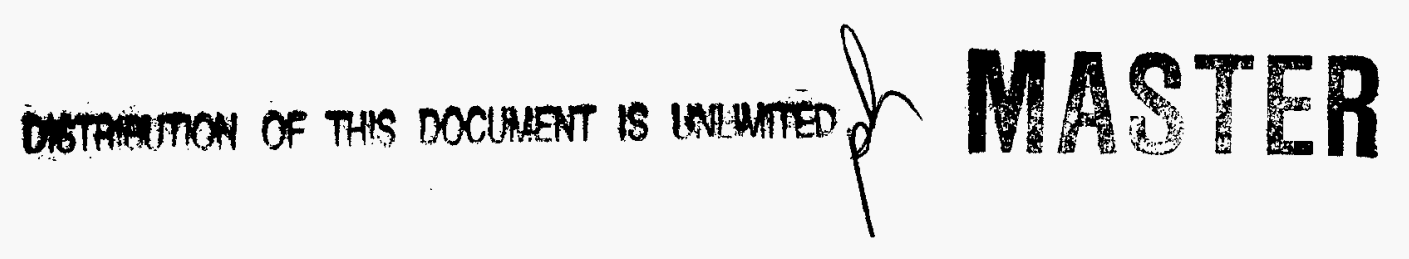

\section{0}




\section{DISCLAIMER}

This report was prepared as an account of work sponsored by an agency of the United States Government. Neither the United States Government nor any agency thereof, nor any of their employees, makes any warranty, express or implied, or assumes any legal liability or responsibility for the accuracy, completeness, or usefulness of any information, apparatus, product, or process disclosed, or represents that its use would not infringe privately owned rights. Reference herein to any specific commercial product, process, or service by trade name, trademark, manufacturer, or otherwise does not necessarily constitute or imply its endorsement, recommendation, or favoring by the United States Government or any agency thereof. The views and opinions of authors expressed herein do not necessarily state or reflect those of the United States Government or any agency thereof. 


\section{TABLE OF CONTENTS}

ACKNOWLEDGEMENTS ...................... 1

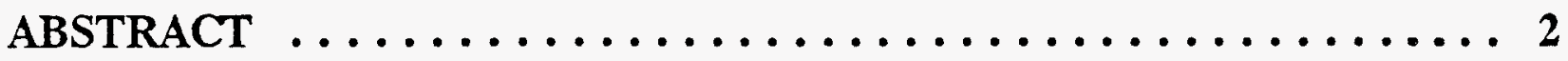
INTRODUCTION $\ldots \ldots \ldots \ldots \ldots \ldots \ldots \ldots \ldots \ldots \ldots \ldots \ldots$ METHODOLOGY $\ldots \ldots \ldots \ldots \ldots \ldots \ldots \ldots \ldots \ldots \ldots \ldots$

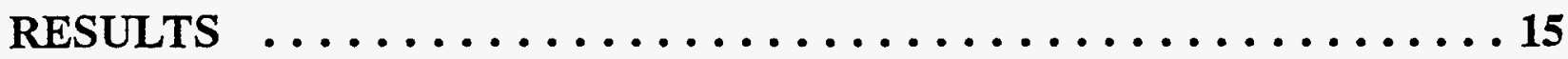

DISCUSSION ............................. 19

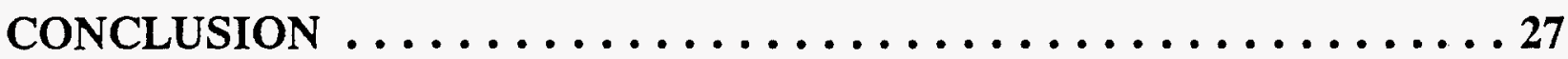
BIBLIOGRAPHY $\ldots \ldots \ldots \ldots \ldots \ldots \ldots \ldots \ldots \ldots \ldots \ldots \ldots \ldots \ldots \ldots \ldots$ BIOGRAPHICAL SKETCH $\ldots \ldots \ldots \ldots \ldots \ldots \ldots \ldots \ldots \ldots \ldots$ LIST OF FIGURES $\ldots \ldots \ldots \ldots \ldots \ldots \ldots \ldots \ldots \ldots \ldots \ldots \ldots \ldots \ldots \ldots$

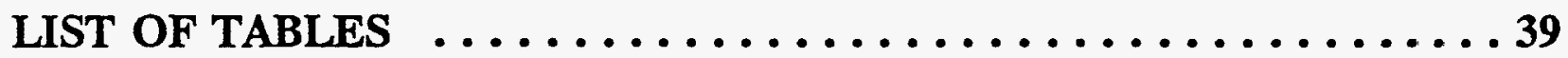




\section{ACKNOWLEDGEMENTS}

I would like gratefully to acknowledge the opportunity afforded me to study at Brookhaven National Laboratory by the Health Physics Fellowship Program sponsored by the Department of Energy, and administered by Oak Ridge Associated Universities, without whose dedication to the advancement of scientific knowledge this study would not have been possible.

Special thanks go to the "Hot Particle" research team at the laboratory which includes Drs. John Baum, Arland Carsten and Darryl Kaurin. Darryl's broad understanding of issues relating to hot particles made it much easier to define an area of research which would be rewarding for me and beneficial to Brookhaven as well.

The largest debt of gratitude is owed to my wife, Lea. It was her wisdom that I pursue a graduate degree that led to our decision to come to Florida. She has worked selflessly to support our family, taking some of that burden off my shoulders so that I could study without anxiety. She has sacrificed more than I could have asked so that we could seize the opportunity to invest in our future. To her I say thank you for making this possible, and for never failing to believe that this was the best decision for us.

Brookhaven's data analysis and interpretation of results is not yet complete, and, therefore, this report is not for publication, citation or distribution. The research was performed under appointment to the Applied Health Physics Fellowship program administered by Oak Ridge Institute for Science and Education for the U.S. Department of Energy. 


\section{ABSTRACT}

The purpose of this project was to compare the effectiveness of hot particles with different energy betas in producing ulcers on-skin. The sources were man-made "hot particles" similar in size and activity to those found in the commercial nuclear power industry. Four different particle types were used. These were thulium (Tm-170) with a 0.97 $\mathrm{MeV}$ maximum energy beta, ytterbium (Yb-175) with a maximum beta energy of $0.47 \mathrm{MeV}$, scandium (Sc-46) with a $0.36 \mathrm{MeV}$ beta, which was used as a surrogate for cobalt-60 (0.31 $\mathrm{MeV}$ beta) and uranium (in the carbide form) with an average maximum beta energy of about $2.5 \mathrm{MeV}$.

Since higher energy beta particles penetrate further in skin, they will affect a higher number and different populations of target cells. The experiments were designed as threshold studies such that the dose needed to produce ulcers ten percent of the time (ED10\%) for each particle type could be compared against each other. The particle type with the lowest ED10\% was presumed to be the most effective, that is, equivalent doses would result in the highest percentage of ulcers for the most effective ulcer producing particle type. These scab incidence studies are being funded by the Nuclear Regulatory Commission under contract FIN A-3990-4 to aid in future rulemaking decisions.

Current findings indicate that ytterbium is the most effective ulcer producing particle type, and that as average beta energy is increased, the dose needed to produce ulcers in $10 \%$ of exposures(ED10) also increases. It is believed that this effect is primarily due to the way that lower energy beta particles deposit most of their dose near the skin's surface. 


\section{INTRODUCTION}

Hot Particles are small bits of activated material from pipe and valve surfaces in nuclear power plants, or they are small pieces-of nuclear fuel fragments which typically break free from the supportive fuel cladding and circulate in the primary coolant until they plate out on pipe surfaces. In the latter case, these fuel particles contain uranium and its fission daughters. These hot particles are of importance as a radiological protection issue, and as a biological hazard since they can impart a large dose to a small area of the body. This highly non-uniform exposure contrasts strongly to the whole body exposures whose risks are primarily stochastic in nature, and for this reason the deterministic biological endpoints of concern and their thresholds are being studied here in the United States and in the United Kingdom

This project focuses on the effects these hot particles have on skin, since most are beta emitters. Specifically, comparisons have been made for the thresholds of uranium carbide, thulium, scandium and ytterbium. Uranium carbide is a surrogate for reactor fuel, and has a maximum beta energy that is strongly dependent upon the length of irradiation and time post irradiation. In these studies particles used had an average maximum beta energy of about $2.5 \mathrm{MeV}$. Thulium was used because it has a maximum beta energy of about $1 \mathrm{MeV}$ which is intermediate between the high and low beta energies, and because it has been studied by other researchers. Ytterbium has a $0.47 \mathrm{MeV}$ beta, and scandium has a $0.36 \mathrm{MeV}$ beta, which is an excellent surrogate for the $0.31 \mathrm{MeV}$ beta given off by cobalt60 , the activation product of concern in most nuclear power plants. Also, it emits two gammas of about one $\mathrm{MeV}$ each for every disintegration of the nucleus, similar to cobalt- 60 . 
The biological endpoint scored were skin ulcerations, which by definition are a break in the integrity of the skin which can become infected and lead to other health problems, not to mention their embarassing cosmetic appearance. Thresholds were determined by probit analysis, a statistical procedure which plots dose tolerance as a percentage against the logarithm of the dose administered. This technique of analysis reduces to the familiar straight line regression from which effective doses which produce $10 \%$ incidence of ulcers were obtained. Because the Nuclear Regulatory Commission stipulated that they wanted thresholds reported as ED10's (doses which produce ulcers with $10 \%$ probability) with $95 \%$ confidence limits for the other analyses Brookhaven was conducting, it was decided that the same convention ought to be applied in this analysis for the sake of standardization and comparison of results.

Experiments conducted this summer included only scandium and ytterbium. The thulium exposures were carried out in 1992, and the uranium carbide were carried out in 1991. Also, a range finding experiment for ytterbium was conducted in 1992 to determine the dose range which a more extensive future threshold study should focus on. This project then has two purposes: to determine if conclusions drawn from the uranium carbide and thulium databases suggest that higher energy beta emitters are more effective at producing skin ulcers ( a lower ED10) and that therefore additional exposures with uranium carbide to better define its ED10 value should be sanctioned, and to determine if different energy beta particles will cause the same proportion of skin ulcers if equal doses of each were to be applied to the basal layer of cells, depth 70 microns, and averaged over one square centimeter. 


\section{METHODOLOGY}

Since these are threshold studies, and results are largely dependent upon how data are obtained and analyzed, it is appropriate to begin by discussing the basis of probit analysis. Biological organisms exhibit a tolerance distribution, similar to that of Figure 1, for ingestion of toxins. For quantized response data, such as lesions, the dose needed to produce the reaction will vary between individuals. Therefore, it is necessary to consider the distribution of tolerances over the population being studied. That is

$$
d P=f(\lambda) d \lambda
$$

A proportion $\mathrm{dP}$ of the entire population being tested has tolerances lying between $\lambda$ and $\lambda+d \lambda$ where $d \lambda$ represents a small increment of applied dose and $f(\lambda)$ is some distribution function. The distribution is noticeably skewed to the left, with few members of the population having a large tolerance at high doses. It is often possible to obtain an approximately normal distribution by transforming the dose scale from linear to logarithmic. The resultant curve is shown in Figure 2, and the cumulative normal curve is shown in Figure 3.

In these types of threshold experiments, the probability of a pig skin site developing an ulcer after exposure to a hot particle follows a binomial distribution. It is a binomial event: either there will eventually be or there will not ever be an ulcer as a result of the exposure. Given that a number $\mathrm{N}$ of pig skin sites were given a particular dose of beta radiation, one would expect the percentage developing ulcers to be $P$, and those not responding to be ( $1-\mathrm{P})$. The average number responding in repeated batches of size $\mathrm{N}$ 
would be $N^{*} \mathrm{P}$. For a series of ascending doses we would expect to obtain correspondingly larger values of $\mathrm{P}$. The probit of the proportion $\mathrm{P}$ is defined as the abscissa which corresponds to a probability $\mathrm{P}$ in a normal distribution with mean 5 and variance of 1 . Of course, five standard deviations will not include $100 \%$ of the data, since a fraction of normally distributed data will fall outside this range. The problem of how to use real life $0 \%$ and $100 \%$ data points is overcome in SAS by assigning these points a finite weighting so that they can be included in the probit computations. The Probit transformation is plotted in Figure 4. It essentially straightens out the normal sigmoid curve allowing the more familiar technique of regression analysis to be performed on data which is expressed as percentages.

Once the limit to which the regression line tends has been computed by maximum likelihood estimates, inverse prediction is used to determine the dose which will cause a predicted proportion of ulcers. Since the ordinate is regressed on the abscissa, it is not appropriate to use normal predictive methods to establish the uncertainties associated with a predicted dose. Rather, the concept of fiducial probabilities is employed. D. H. Finney in his book on probit analysis elaborates on fiducial probabilities and makes two fundamental points about calculating limits ${ }^{1}$. The first of these is

$$
K m=\frac{1}{\left(b^{2}\right)}\left|\frac{1}{\sum n W}+\frac{(m \bar{x})^{2}}{\sum n W(x-\bar{x})^{2}}\right|
$$

The variance of a particlular dose point $m$ is comprised of two parts. It is inversely proportional to the sum of the products of the number of replicated exposures and probit weighting factors, and it is directly proportional to its separation from the mean dose. Therefore, the uncertainty in a probit regression is least at the median dose and greatest at 
the minimal and maximal doses. The confidence interval for $\mu$, of which $\mathrm{m}$ is only an estimate, becomes $m-z_{1-\alpha / 2} s_{m}$ and $m+z_{1-\alpha / 2} s_{m}$, for a $(1-\alpha)$ confidence interval.

The second major point about fiducial limits which Finney makes concerns the heterogeneity of the data. The $\chi^{2}$ value associated with the probit regression is a weighted sum of squares of the differences between the expected (predicted) and observed proportions of ulcers over all dose points. A significant $\chi^{2}$ indicates that there is heterogeneity of departure of the plotted points from the regression line, and confidence limits must be based on the t-distribution. When the $\chi^{2}$ value is not significant, confidence limits may be based on critical values taken from the normal distribution. This is most important when dealing with thresholds where the uncertainty in a predicted effective dose can extend to zero on the lower side, or lie above the lower limit of another isotopic threshold on the upper side.

One of the questions that had to be answered with regard to the experimental design was how many dose replications to use at the lowest dose point where we were expecting near zero incidence. Ordinarily an estimate of the true standard error would be the square root of the number of events observed, but this approximation does not work when zero events are recorded. What was desired was a way to be able to assign an error bar on a zero incidence point which corresponded to the upper side of a $95 \%$ confidence band. In other words, the error bar on $0 \%$ incidence would be set at $2 \sigma$. Another way of asking the same question is what is the value of $\mathrm{p}$, the probability of observing an event in one trial, such that the observation of zero events in $\mathbf{n}$ trials is exactly two standard deviations less than pn? From binomial statistics 


$$
\begin{array}{ll}
P(X)=\frac{n ! p^{x}(1-p)^{n-x}}{x !(n-x) !} & \\
P(0)=(1-p)^{n} & , x=0 \\
\sigma^{2}=p n(1-p) \quad, \text { definition of variance for } \\
\text { pn }-2 \sigma=0 & \text { the binomial distribution }
\end{array}
$$

(observing zero ulcers out of $\mathbf{n}$ replicated dose points is 2 sigma less than $\mathrm{pn}$ )

$$
\begin{aligned}
& \mathrm{pn}-2(\mathrm{pn}(1-\mathrm{p}))^{1 / 2}=0 \\
& \mathrm{pn}=4(1-\mathrm{p}) \\
& \mathrm{p}(\mathrm{n}+4)=4 \\
& \mathrm{p}=4 /(\mathrm{n}+4)
\end{aligned}
$$

Given $n$ events at the lowest dose, this is the value of $\mathrm{p}$ which would be $2 \sigma$ away from an observed incidence of $0 \%$. Restricting $\mathrm{p}$ to $\leq 0.1$ told us that 36 exposures at the lowest dose points should be used in order to be able to say with $95 \%$ confidence that an observed $0 \%$ incidence at that dose would lie in the $0-10 \%$ incidence range. Because a one-sided confidence interval accompanies a zero point, tables of one-sided proportions for various confidence levels and number of replicates were referenced ${ }^{2}$. This yielded 28 as an appropriate number of replicates to satisfy our confidence requirements. 
The other variable in data analysis was scoring technique, that is, the process by which lesions were actually scored as ulcers. The experimental protocol called for two scorers to score the pigs daily. For the first three weeks, each flank was scored three times, left and right sides alternating on opposite days.- Beginning with the fourth week out to 70 days, each side was scored twice weekly. The scoring method employed by Dr. John Hopewell of the United Kingdom, who is also conducting hot particle experiments with swine, calls a recorded lesion a scab only if it is seen by both observers on consecutive scoring days for that side.

The original scoring protocol employed by Brookhaven several years ago for the first series of hot particle exposures called a lesion a scab if two observers saw it three times each in a scoring period. The scoring periods were 28,48 and 71 days. The consecutive scoring day criteria used by Dr. Hopewell seemed too restrictive because some late appearing scabs seem to be transient. The Brookhaven method seemed too liberal because it did not adequately discriminate against false positives. Performing probit analysis on the same data sets using both scoring techniques clearly showed that the ED10\% values obtained differed by as much as a factor of three, as is shown in Table 1 .

It was decided that for this analysis a hybrid scoring technique would be used. Lesions were only recorded for analysis if they had been positively identified four out of six possible person-scoring days. For example, if the left side of a swine is observed on Monday, Wednesday and Friday by two people each day, then there were a total of six scoring opportunities. The scab must have been independently observed and recorded at least four times, no more than twice by the same observer. In this way a scab which is seen three consecutive times by the same observer, but only once by the other observer, will not be analyzed as an ulcer, because the data would be disproportionately biased by one 
observer, an effect it was hoped would be excluded by the use of at least two observers.

The last problem which needed resolving was how to handle question marks, since on occassion an observer would see something, but was not convinced that it was a scab. In this case it went into the database as a question mark along with other required data which were:scab size in millimeters, scab location in the grid, and whether the scab was pigmented or white. It was decided to include question mark entries only if the scab size recorded was greater than 1 millimeter, because the unaided human eye cannot distinguish scabs smaller than this from other markings on the skin while the subject is moving. Also, to limit uncertainty in the analysis, it must have been the only question mark about the exposed site in three consecutive scoring periods. For example, if both observers recorded a scab for site A-3 on Monday, neither recorded it on Wednesday, one positively recorded it on Friday while the other put it down as a questionable scab one millimeter in size, it would not be analyzed as a definite ulcer for inclusion in probit analysis.

The second part of the experiment's methodology is its protocol; how it was carried out. Hanford mini swine, which were between two and three months of age, were secured from Charles River Laboratories in New Hampshire. It was desired to irradiate the pigs at three months of age since at this age their skin is remarkably similar in structure and kinetics to that of humans. They were housed on site in the Brookhaven Medical Department building where veterinary services were available. The pigs were trained to walk up a ramp which had plexiglas viewing windows by placing their food bowls in a retainer at the ramp's end. In this way, one could observe the exposed sites during feeding time each day with the help of a handheld lamp. Each pig was observed separately, being led back to its pen before another was released. Toothbrushes were used to gently remove feces that had dried onto the flank in order to avoid recording them as potential scabs. 
One week before the pig was to be irradiated it was anesthetized, and each flank tatooed. The grid consisted of columns one through ten, and rows A through F. In this manner about 45 useable one inch by one inch square exposure sites were obtained. Several biopsies from each side were also taken to get-information on keratin layer thickness, the dead layer of hardened, stratified cells which aid in shielding the underlying basal cells from beta particles.

The particles used for irradiation were prepared on site. Particles which had an effective diameter of about 450 micrometers ( 0.45 millimeters) were desired for several reasons. First, it was felt that particles less than one millimeter in diameter best represented the size of particles to be encountered in power plants. Second, for the gamma emitting scandium particles, the beta dose should be between five and six times greater than the gamma dose at 70 microns depth in the skin averaged over one square centimeter, since this typifies the beta to gamma dose ratio of a 100 micron diameter cobalt-60 particle on the skin. This ratio decreases with increasing diameter of the particle due to self shielding of betas. The last consideration was activation time. Enough atomic targets were needed so that desired activities of four to twenty millicuries per particle could be reached without unduly delaying the experiment.

Particles were prepared from 128 micron thick sheets of $99.9 \%$ pure scandium and ytterbium. Thin strips were first cut with a razor blade, and then particles were cut using a 200 micron diameter gold wire as a reference. After cutting a batch of 10 candidate particles, a high powered microscope with a $20 \mathrm{X}$ power objective lens was used to measure the length and width of the particle on both faces, resulting in eight measurements. The objective lens had a linearly divisioned scale which had previously been calibrated in microns per division so that measurements could be converted to microns. Assuming a semi- 
pyramidal shape for the particles, an effective volume was determined which was used to obtain the mass. Mass desired was calculated from expected irradiation times in Broohhaven's High Flux Beam Reactor and from desired activities. The fluence for each beam port was a known quantity, as were the other nuclear parameters such as cross section.

The activated particles were mounted in a semi-hot cell on placement blocks which were about one inch square, and which were placed on the one inch square grids tatooed on the swine flanks. The blocks were made of styrofoam to minimize backscattering of betas. On either side of the block, double sided sticky foam tape was placed. On the rear side of the block this tape served to secure a velcro tab which would aid in handling the block with another piece of velcro attached to a lucite pole. The front piece of tape was used to secure the particle to the block. Once the particle was centered, a piece of radiation-resistant Kapton 15 microns thick was placed over the particle to prevent the spread of possible contamination from the placement block to the swine skin. During actual exposures the particle placement blocks were secured to the exposure sites during long exposures using a denim harness with elastic straps. The block was placed on the skin, and directly below one of the straps. It was concluded that this arrangement would preclude the particle from being separated by a small air gap from the skin, which would affect the desired dosimetry, while at the same time preventing blood flow to the particle site from being constricted.

Both the ytterbium and scandium dose response experiments consisted of five dose points, the lower dose points having more replicates than the higher doses. Three swine flanks were dedicated to each radioactive particle type, providing about 135 available sites for exposure. From these, 28 were used as controls to ascertain whether potential insect bites were being consistently scored as lesions. The observers did not know which flanks 
had received exposure from either hot particle. More importantly, they did not know what dose, if any, each site had received so as not to bias their observations. All observations were entered into a spreadsheet database, and were catalogued by date, grid number, pigmenatation (if any), size, and location within each site. Size, color and location were subjectively recorded. No scales or calibrated instruments of any kind were used when recording observations.

In order to do the analysis on declared ulcers, it was necessary to have precise knowledge of doses averaged over one square centimeter at 70 microns depth, the average depth of the basal cell population, as used by the ICRP ${ }^{4}$ and NCRPs. Radiochromic dye film was used to determine these doses. Stacks of three films were irradiated by the particles used in the experiment to determine the doses at different depths. Each film consisted of a $6.5 \mu \mathrm{m}$ thick radiation sensitive-dye layer on a $99 \mu \mathrm{m}$ thick polyester base. When either gamma rays or charged particles interact with the dye and deposit dose, the dye layer turns an increasingly darker color of blue. The exposed films along with some non-exposed films from the same batch were sent to Dr. Soares at the National Institute of Standards and Technology (NIST) where the unexposed films were exposed to known doses of radiation and used to calibrate his scanning laser densitometer. Dr. Soares calculated the dose rate averaged over one square centimeter at 111 and 4 microns, the effective depths of the centers of the top two dye films. With these measurements, it was then possible to calculate the dose rates averaged over one square centimeter at 70 microns depth using the following relation:

$$
\begin{aligned}
\operatorname{DOSE}(70 \mu \mathrm{m}, \text { tissue })=\operatorname{DOSE}(\mathrm{film}, 111 \mu \mathrm{m}) \times \frac{\operatorname{DOSE}(\operatorname{VARSKIN}, 70 \mu \mathrm{M}, \text { tissue) }}{\operatorname{DOSE}(V A R S K I N, 111 \mu \mathrm{m}, \text { film })}
\end{aligned}
$$


VARSKIN MOD 2 is a computer code, designed by Dr. Durham of Pacific Northwest Laboratories, for use principally by the NRC. Its sole purpose is to calculate dose in the skin at any depth the user chooses from hot particles on the skin. All information regarding the isotope, whether mixed or not, is contained in a separate file called Betadata.dat. It also allows for the inclusion of internal conversion and Auger electrons in the calculation of dose. These electrons generally contribute between 1 and $5 \%$ of the dose at shallower skin depths, and are, therefore, significant in determining scab induction. The shielding effects of materials placed between the source and the skin, such as clothing, are also taken into account if the user chooses to include them as parameters. Several source geometries are available, such as point source and rectangular disc, but for VARSKIN MOD 2, the most recent version, the circular disc finite thickness geometry provides the most accurate results. 


\section{RESULTS}

The uranium carbide data was grouped in several different ways to allow for probit analysis. Since the exposures were carried out in a range-finding manner rather than as a threshold determination, similar doses were grouped, the average dose per group being used in the analysis. Data for the two pigs exposed to uranium carbide is listed in Table 2, and results of probit analysis for the different group arrangements is in Table 3 under the headings group A and group B. Though limited, the data suggests an ED10\% value of between 5 and $6 \mathrm{~Gy}$ for the uranium carbide, with a lower $95 \%$ confidence limit of $1 \mathrm{~Gy}$ and an upper $95 \%$ confidence limit of about $8.5 \mathrm{~Gy}$.

Additionally, regressions of resultant scab diameters on the logarithm of dose were carried out to obtain a second measure of the threshold dose, the dose which will produce a zero diameter scab. It should be noted that this is the methodology employed by the National Council on Radiation Protection and Measurements (NCRP) in their report on hot particles (NCRP Rpt. 106). Though polynomial and power fits were tried, the regression on $\log$ of dose fit the data best. The threshold doses determined this way ranged from 4.4 to 9.1 Gy, supporting the 5 Gy determination by probit analysis. Again, these dose values were averaged over one square centimeter at 70 microns depth in the skin, the average depth of the basal cell target population.

Analysis of thulium (1.0 MeV beta energy) induced scabs using the scab incidence technique and probit analysis showed the ED10\% dose to be substantially lower than for uranium carbide. Since this was a true threshold study it was possible to calculate ED10\% values as a function of days post irradiation (DPI). This data set was used to show the different results obtained by analyzing the data with different scoring techniques. This initial 
analysis was used in helping to define the scoring technique which is presently being used by Brookhaven hot particle researchers. The results of the six different scoring techniques and that employed in this project are summarized in Table 1.

Because scab induction was scored on a near daily basis, information concerning time of appearance for scabs produced by varied doses was available for analysis to determine if time of appearance could be correlated to the turnover time of the epidermal cell population. Dr. Archambeau has noted that the turnover time of the epidermis is about 30 days $^{6}$, so that any radiation damage to the supporting population of basal cells would express itself after this time period. Late appearing lesions were observed which began to manifest themselves around 34 days post irradiation. These lesions were all from sites that had received lower doses.

When probit analysis was conducted on the thulium data set, an ED10\% value of about 2.0 Gy was determined, upper and lower $95 \%$ confidence limits being 2.62 and 1.26 Gy respectively. The confidence limits were considerably more narrow than any of the other scab incidence experiments because there were about 40 replicates at each of the four dose points compared to a maximum of 28 for the lowest dose points in the scandium and ytterbium experiments. The scandium scab incidence data suggests an ED10\% value of 2.1 Gy, upper and lower $95 \%$ confidence limits being 0.46 and $3.4 \mathrm{~Gy}$. This data, however, is limited. Early in the experiment, the pig which had had both flanks exposed to scandium died from natural causes, leaving only one third of the initial data source. Therefore, as opposed to the ytterbium analysis, the uncertainty associated with the scandium results is much larger. Fortunately, another pig was secured and exposed to the same dose schedule which was lost when the first pig died. At this writing, the data on this new pig is 50 days post irradiation, and it will be at least several more weeks until this data can begin 
to be analyzed with the original scandium data, but early results are encouraging, and indicate agreement with the $2.1 \mathrm{~Gy}$ ED $10 \%$ calculated from the earlier reduced scandium data.

Most surprising of all are the results forytterbium. Since its maximum beta energy is between the maximum energy beta for thulium and scandium, it was expected that the dose response would show an ED10\% value very near to $2.0 \mathrm{~Gy}$. Instead, an ED10\% value of about $0.75 \mathrm{~Gy}$ was determined, upper and lower $95 \%$ confidence limits being 0.34 and $1.21 \mathrm{~Gy}$. While surprising, it might have been expected on the basis of an earlier range finding experiment carried out at 1.3 and $5.1 \mathrm{~Gy}$. This earlier experiment showed the dose response to be rather flat between these two doses, each one producing about $50 \%$ scab incidence based on 30 and 10 replicates per dose respectively, and suggesting an ED10\% value lower than $1.3 \mathrm{~Gy}$.

The observed persistence of scabs was remarkably consistent. By this it is meant that the sites receiving the highest doses generally showed scabs for the longest period of consecutive scoring days, while the sites receiving the lowest doses tended only to be observed for two or at the most three consecutive scoring days. This suggests that the healing time for higher dose ulcers is longer than for ulcers produced by smaller doses of beta radiation. These low dose scabs also appeared much later than the high dose scabs, thirty or more days post irradiation as compared to fourteen to eighteen days for the high dose sites. This is in agreement with work that has already been done, by Drs. John Hopewell and Monty Charles of the United Kingdom, using discrete hot particles (personal communication, Sept. 1994).

In order that comparison of results for the different isotopes be meaningful, all particles were sized to be similar in size. All four particle diameters were less than 500 
microns $(0.5 \mathrm{~mm})$. This effectively prevented particle size from biasing any conclusions, since larger particles produce the same size scab at lower doses. Also, with the exception of the uranium carbide pigs, all others were between 3 and 4 months old. The uranium carbide pigs were 6 and 8 months old. Brookhaven researchers had previously shown that animals 12-15 months old showed a lower sensitivity to the effects of ionizing radiation on skin.

A cursory analysis of scab site versus flank location has also shown that there is no flank location where scabs are preferentially induced for similar doses. The dose schedules per side were created so that replicated doses were not spatially clustered, but were spread out across high/low and anterior/posterior flank positions. It was thought that the variations in skin thickness might cause a higher proportion of scabs to be induced where the skin was thinner, but this effect was not observed on the animals used in this experiment. 


\section{DISCUSSION}

During the second week of September Brookhaven's Radiological Science Division, headed by Dr. Baum, hosted their second Hot Particle Conference. Attendees included Drs. Hopewell and Charles from England, Dr. J. Durham from Pacific Northwest Labs, Matt Scannell from the Yankee Nuclear Power Plant, Dr. Don Forbes, and Nuclear Regulatory Commission project managers Jack Bell and Stuart Schneider. The conference enabled the Brookhaven research team to present the most recent findings on their hot particle studies for peer review and comment. It also enabled an intercomparison of dosimetry methods to be performed on thulium, cobalt, scandium and ytterbium hot particles using dye film, extrapolation chamber, and other methods. There was ample discussion of scoring technique, and also of the characteristics of radiation-induced skin lesions which would be of concern for health reasons. In order to contrast what these researchers would classify as a lesion against what the Broohhaven observers have been recording as lesions, all pigs exposed to hot particles were observed by conference attendees. It was hoped that these efforts would provide some standardization of methods employed by the foremost researchers into the effects of hot particles on skin, as well as validate the procedures currently in use by the Brookhaven research team.

The uranium carbide results are not conclusive. It cannot be said with the desired degree of confidence that the $10 \%$ incidence dose of about $5 \mathrm{~Gy}$ is a higher threshold than that of scandium or ytterbium, since the lower side uncertainty of $1 \mathrm{~Gy}$ extends below the $10 \%$ incidence for scandium ( $2.1 \mathrm{~Gy}$ ), and is also lower than the upper confidence limit for ytterbium as can be seen on Figure 7. It can also be argued that it is not reasonable to perform a regression of scab diameter on the log of dose because dose may be administered 
in such a narrowly collimated fashion as to cause no breaks in the skin, even though sufficiently large doses are applied.

In favor of the higher $5 \mathrm{~Gy}$ incidence level for beta energies of about $2.5 \mathrm{MeV}$, however, is the fact that of 18 dose points ranging from 0.64 to $4.79 \mathrm{~Gy}$ not one resulted in an observable scab. When doses as high as $10.73 \mathrm{~Gy}$ are considered, the incidence is only $8.3 \%(2 / 24)$. Another piece of older evidence for a higher $10 \%$ incidence is research conducted by Dr. Forbes with uranium carbide in 1971. The regression of his data of scab diameter on dose gives threshold doses two and three times higher than that of Brookhavens' threshold. While the evidence is not conclusive, it was strong enough to suggest to the Brookhaven research team that the higher energy beta-emitting particles are not as effective in producing lesions as the lower beta energies of other isotopes, even though those produced are more persistent, and that it would not be in the best interests of the project to further investigate the uranium carbide threshold by performing another pig exposure with this average beta energy. However, analysis of the uranium carbide data is ongoing.

The thulium data, however, is statistically more significant because it was a true threshold study, and because a very large number of replicates were given for each dose. Lending additional support to the argument of a $10 \%$ incidence near 2 Gy are the results of Dr. Hopewell, who in 1991 published results of his research using thulium particles from 0.1 to 22 millimeters in size to study the specific biological responses of the skin after exposure to beta particles of various energies ${ }^{7}$. He points out that acute breakdown of pig skin after exposure to a 0.5 millimeter thulium source occurs at a surface dose of $188 \mathrm{~Gy}$ where 16 microns depth is defined as the surface, and doses are per 1.1 square millimeters. After conversion to dose per square centimeter, and using VARSKIN to estimate the 
percentage of that dose that will be received at $70 \mu \mathrm{m}$, this comes out to $2.06 \mathrm{~Gy}$. This is specifically for the biological endpoint of what he terms "acute ulceration", whereas Brookhaven does not differentiate between endpoints, but determines thresholds on the basis of whether or not scabs were seen. However, because of the similarity in particle size and experimental protocol, the $2.0 \mathrm{~Gy}$ and $2.06 \mathrm{~Gy}$ ED10 values focus attention more on the $1.0 \mathrm{MeV}$ beta than on the higher energy beta of UC2 and its ED10 of about $5 \mathrm{~Gy}$.

Implicit to this discussion are the aspects of particle size, which affects the size of the field irradiated, and the associated thresholds. It has been well documented that as the size of the field irradiated increases, as is the case with medical $x$ rays, the dose needed to produce a particular biological reaction decreases. It has been suggested, but not documented, that the variable which defines the difference between these effects is the maximum transit length of clonogenic cells. That is to say that once the field size irradiated exceeds the distance that surviving basal cells can transit from the periphery of the irradiated area, this mitigating factor is removed and the effective dose needed to produce any type of biological damage decreases abruptly.

Following this line of reasoning, the factor which probably most impacts the persistence of lesions is the relative survival of basal cells which are situated along the canal of hair follicles. Assuming equal doses of both high and lower energy betas, the higher persistence (slower healing rate) of the higher beta energy ulcers can be attributed to the lesser survival of clonogenic cells in the hair follicles, which would ultimately repopulate the exposed area. Since all basal cells along the base of the epidermis would be lost, the only source for repopulation would be those which survived in the hair canals. The loss of basal cells should not be viewed as an abrupt event. Rather, it is observed in swine that basal cells are lost at a rate of between 2.5 and $4 \%$ per days. This rate of loss is consistent with 
the appearance of late forming scabs at the 30 to 35 day mark post irradiation. Hopewell has stated that for irradiation with $\mathrm{X}$ rays "the maximum reduction in basal cell number is dose related, but the rate of reduction in cell number is independent of dose."

Finally, it must be noted that in addition to basal cells, the endothelial cells in the superficial papillary dermis are also a target for the $1.0 \mathrm{MeV}$ and above betas. Unlike basal cells, endothelial proliferation has never been observed. Therefore, the cause of damage would be cell loss without replacement. As Archambeau notes, "the changes seen histologically are cell loss, a decrease in the number of vessel lumens seen on microscopic section, a decrease in tuft density and dialation." These cells are in the vasculature system, which supplies oxygen and nutrients via capillaries to the epidermis. The way in which these different target populations of cells interact must be taken into consideration when ascertaining the reasons behind different thresholds for different energy beta particles.

As noted previously, the results for ytterbium were the most surprising. The scandium threshold was lower as expected, but efforts to explain why ytterbium has the lowest observed $10 \%$ incidence value have failed. Since the skin is a very complex organ, and its reponses to ionizing radiation depend on multiple factors, it would be simplistic to assume that a model incorporating beta energy alone could account for and explain all manifestations of radiation damage. The distribution of dose with depth is certainly an important parameter, and Figure 5 shows the basic structure and critical depths in the skin. It also shows the maximum range that an average energy beta particle from the three studied isotopes would travel. For convenience, average energies were calculated as one third of the maximum beta energy for each of the three beta spectra. According to well established range-energy curves for beta rays in tissue, the ranges of the maximum energy beta particles would be three times deeper, but it was decided that average values better 
represented the critical range to consider when assessing the cell populations at risk, since a higher fraction of total beta particles would deposit dose at ranges equal to or less than this range

To further amplify this point, Figure 8 depicts the depth dose distributions for the average beta energy from the three primary hot particle types ${ }^{9}$. The basal cell layer and the average depth of the vasculature in the papillary dermis $(350 \mu \mathrm{m})$ are displayed, as are the percentage of the surface dose they would receive from a hot particle on the $\operatorname{skin}^{10}$. These percentages were calculated from VARSKIN MOD 2, currently the only calculational model recognized by the NRC for hot particle dosimetry. This diagram shows that in order for ytterbium particles to deliver a significant dose to the vasculature, the dose received by the basal cells might be so large as to initiate an ulcerative condition before the damage in the vasculature could be expressed. The gamma component for scandium explains why the relative dose received at deeper depths is larger than for ytterbium, because for equal activities, ytterbium's larger average energy beta spectrum should deliver a larger beta dose at all depths.

Another important parameter in modeling radiation damage to the skin is the volume of the skin exposed. For pure beta emitters, volume irradiated depends only upon the maximum beta energy. It is appropriate at this point to begin looking at synergistic relationships within the structure of the skin. That is, can there be one average beta energy which is more effective in producing damage because its effect is multiplied by a biologically meaningful synergism? Archambeau indirectly argues this point when he models skin damage on the basis of what he calls a "skin functional unit." He says that a skin functional unit is the smallest unit of skin that retains all the characteristics of skin, and is roughly $\mathbf{3 0}$ $\mu \mathrm{m}$ in diameter and $350 \mu \mathrm{m}$ in length. This model emphasizes that the dose response of the 
skin functional unit defines the dose response of the skin. He further says that the preservation of skin integrity following irradiation rests on survival of at least a minimum number density of skin units. He views the loss of endothelial cells in the vasculature as the cause for the loss of any functional unit. It is believed his model of skin damage is on the right track, but could be taken to the next level if he were able to incorporate average beta energy from hot particles in modelling skin functional unit loss.

To more clearly understand the consternation that ytterbium has produced, Figure 7 was plotted to show the ED10\% values as a function of maximum beta energy. If the three scabs observed at the lowest doses of 0.31 and 0.62 Gy are thrown out, the ED10\% for $\mathrm{Yb}-175$ rises to $1.25 \mathrm{~Gy}$, which only improves the picture slightly. However, the scabs definitely met the scoring criteria and so should be included in the analysis. This was simply said to illustrate the difficulty in explaining the ytterbium dose response.

Figure 7 deserves explanation. It suggests that the physical mechanisms which produce ulcers change as beta energy is reduced. The relative minimum at ytterbium (avg. beta energy $0.145 \mathrm{MeV}$ ) indicates a high degree of effectiveness at producing ulcers per unit dose. This means that the dose is clustered around the 70 micron basal cell depth. Below these energies a larger surface dose is required to produce the same degree of cellular damage at 70 microns because of the lower penetrating ability of the scandium betas (avg. beta energy energy $0.11 \mathrm{MeV}$ ). The surface dose becomes so high that a reaction in the viable post mitotic suprabasal cells is initiated before damage to the basal cells themselves can be expressed. The mechanism of ulceration changes from basal cell loss to suprabasal cellular necrosis. This is also why the similar ED10 values for thulium ( $2 \mathrm{~Gy})$ and scandium (2.1 Gy) have no basis for comparison.

The question of how many days post irradiation to score the pigs arose at the hot 
particle conference in order to provide a practical guideline to those who may have or may some day receive dose from hot particles. It was found that the best way to answer this question was to plot the ED10\% values as a function of DPI. In this way one could predict where the values would level or bottom out based on the graphical trend. The results are plotted in Figure 6. After every third or fourth day probit analysis was run on the updated observational database. ED10\% values were tabulated ( Tables 4,5,6) over the course of the experiment, and the plot was updated weekly. There was no general agreement on the significance of the plot when it was presented at the hot particle conference. Dr. Charles thought it suggested broad agreement among all the radioactive particle types used, while others tended to doubt the statistical reliability of the supporting data, especially at the low dose points where there was already skepticism. It was recommended that additional exposures at or near the ED10\% for both ytterbium and scandium be performed in order to validate the existing data. These exposures were performed in September, and the data is supporting rather than contravening earlier experimental results.

Finally, Figure 9 is a plot of the probit results for all four different radioactive particles, with the $95 \%$ confidence limits for uranium carbide and ytterbium included at the $10 \%$ incidence level to show the very slight overlap. This plot shows that while ytterbium may have the lowest ED10\% value, it also has the highest ED90\% value. That is, the slope, the change in incidence of lesions per Gray received is less than for the other three hot particles. This may be explained by the smaller volume of target cells irradiated which may act as a stimulus for migration of healthy cells from the periphery of the irradiated area. This effect is observed for irradiations of skin with the same radioactive particle, but with vastly different particle sizes. For example, Hopewell has performed exposures of swine with ${ }^{90} \mathrm{Sr} /{ }^{90} \mathrm{Y}$ for 22.5 and 2 millimeter diameter sources. The ED50\% values for acute skin 
breakdown were $27.3 \mathrm{~Gy}$ for the larger source and $179 \mathrm{~Gy}$ for the smaller source respectively.

The other comment to be made about Figure 9 is the similarity in slope of the uranium carbide and thulium plots, and the ytterbium and scandium plots. The higher energy beta plots have essentially the same slope but are offset, just as are the low energy beta plots. This suggests that the low energy betas and high energy betas affect different populations of target cells which have different radiosensitivities. For the low energy betas the target populations are the viable, post mitotic cells above the basal layer and the basal cells. For the higher energy betas the target populations are the basal cells and the endothelial cells which line the vasculature in the upper papillary dermis. 


\section{CONCLUSION}

The motivation behind the research to determine if there is one beta energy which is more effective at producing skin ulcers than any other is twofold. First, the commercial nuclear power industry has wanted the Nuclear Regulatory Commission to set a regulatory threshold that is less restrictive than the current ICRP recommendation of 0.5 Gy (50 Rem) per year. Secondly, the NRC has commissioned Brookhaven to conduct hot particle research not only to provide evidence for a threshold which can be used in the NRC rulemaking process, but also to help resolve the factor of ten difference in recommendations by the ICRP and NCRP. The 5 Gy per year recommended by the NCRP would be more desirable to the nuclear power industry, while the 0.5 Gy limit recommended by the ICRP would maintain the status quo.

There is now a larger database of experimental hot particle exposures for these two commissions to draw upon. While certainly not conclusive, this new data does add to the limited information previously available. Based solely on scab incidence, and not risk of cancer incidence, 1 Gray would seem to be a reasonable threshold recommendation. This is in agreement with Hopewell's recommendation of a 1 Gy per year dose limit for hot particle exposures, though he refers this limit to a depth of 100-150 microns and not the 70 microns used by the ICRP. This limit would be based on the $0.75 \mathrm{~Gy}$ ED10\% value for $\mathrm{Yb}$ 175 deduced from the Brookhaven scab incidence exposures.

There is disagreement as to the accuracy of the results, since the uranium carbide ED10 value is based upon several of many possible data groupings. However, the analysis of the other three beta energies is sound, and is partially supported by observations from other independent experimenters. Probit analysis is not the sole means by which this type 
of data may be analyzed. It must be noted that other models will fit dose tolerance data with a degree of accuracy similar to or in some instances slightly better than the probit will. Logistic fits were tried earlier in the summer, but in all cases the minor differences from the probit were not sufficient to justify its continued application, especially since excellent documentation was available on probit analysis, but not on logistic analysis.

The experimental design deserves mentioning one more time. These were a series of scab incidence experiments, and not a true threshold study, because scab induction is a statistically governed process, and there will always be some "background noise" which will be impossible to discriminate against The goal was to establish the dose at 70 microns depth averaged over one square centimeter which would, if applied in repeated exposures to different skin sites, result in $10 \%$ of sites developing ulcers, or breaks in the skin which by themselves are not a cancer risk, but because of degrading cosmetic appearance and potential infection could pose more irritating problems. The main difficulty in this type of design is in getting good data at the low incidence dose points. If data is only available for incidence values above $10 \%$, then extrapolations below the lowest dose point based on the regression are required to determine the ED10\% value. If the lowest dose point results in zero scabs being observed, then enough replicates must be used in order to keep the uncertainty acceptably low. Ideally, one would like to use as many points as possible around the point of interest, in this case our ED10\%. Additionally, it is hoped that the lowest dose point provides a value less than or equal to the ED\% value of interest. The lowest dose points in this project were constrained to meet this criteria by using enough replicates to keep the uncertainty to between 0 and $10 \%$. This eliminated the need to extrapolate beyond the range of data. 
Finally, it is difficult to identify biological targets for ionizing radiation, and even more difficult to explain the effects which radiation will have on these targets. This statement is justified by the observation that radiation damage to tissues can only be declared to be radiation-induced if the target cell population is observed dying off after being exposed. The end result, whether it be ulceration of blood vessels, or breaks in the skin, cannot be assigned to a particular cause because different causes produce identical observed effects.

The skin is perhaps the most complex organ after the brain. It consists of stratified layers of cells of different function and composition, it is elastic, varies in physical form from location to location, and is different in color and quality from person to person. Because the functions of different cellular populations are interrelated, an effect on one will to some degree affect others. The damaging effects of radiation are in all likelihood dulled by these interrelationships in some instances, and amplified in others. This makes modelling of radiation damage to tissue difficult, and thus it is believed that the damage that hot particles cause is best modelled based on the gross observable lesions they produce.

The determination of the most effective beta particle energy at producing skin ulcers is one of several main goals of the hot particle research at Brookhaven. Other goals include the determination of the most appropriate area over which to average dose, and an analysis of the persistence of ulcers as a function of beta energy. With this knowledge in hand, Brookhaven's hot particle research team will be in a better position to advise and aid the NRC in its rulemaking process concerning hot particle exposures at nuclear power plants. 


\section{BIBLIOGRAPHY}

1. Finney, D.J., Probit Analysis, Second Edition, 1952

2. Natrella, M.G., Experimental Statistics, National Bureau of Standards, 1963

3. Morris, G.M., Hopewell, J.W., Changes In The Cell Kinetics Of Pig Epidermis After repeated Daily Doses Of $X$ Rays, British Journal of Radiology, vol. 61, pgs. 205-211, 1988

4. ICRP (International Commission On Radiation Protection), The Biological Basis For Dose Limitation In The Skin, ICRP Report 59, Bethesda MD, 1991

5. NCRP(National Commission On Radiation Protection And Measurements), Limit For Exposure To Hot Particles On The Skin, NCRP Report 106, Bethesda MD, 1989

6. Archambeau, J.O., Pathophysiology Of Irradiated Skin And Breast, International Journal of Radiation Oncology, Biology, and Physics, submitted 1994, (personal communication)

7. Hopewell. J.W., Biological Effects Of Irradiation On Skin And Recommended Dose Limits, Radiation Protection Dosimetry, vol. 39, pgs. 11-22, 1991

8. Peel, D.M., Hopewell, J.W., Wells, J., Charles, M.W., Nonstochastic Effects Of Different Energy Beta Emitters On Pig Skin, Radiation Research 99, pgs. 372-81, 1984

9. Hopewell, J.W., Experimental Studies Of Stochastic And Nonstochastic Changes In The Skin, Radiation Protection Dosimetry, vol. 39, pgs. 39-46, 1991

10. Peel, D.M., Hopewell, J.W., Wells, J., Charles, M.W., Late Nonstochastic Changes In Pig Skin After Beta Irradiation, Radiation Research 101, pgs. 491-96, 1985 


\section{BIOGRAPHICAL SKETCH}

Charles Schaefer is a Department of Energy Fellow in the discipline of Applied Health Physics. Before coming to the University of Florida as a graduate student he worked as a Radiochemical Analyst and Health Physics Coordinator for Environmental Physics, Inc., a rapidly growing environmental laboratory in Charleston, SC. Previous to this experience he was a commissioned officer in the United States Naval Submarine Force where his primary duties were in Reactor Operations and supervision. Other duties included the management of several engineering divisions, the most favorable impression having been made by the Water Chemistry and Radcon Group.

Charles has been married for 6 years, and has a two and one half year old son. Currently, he lives in New York, where he was raised, and where he hopes to settle. His career goals are to work in the field of nuclear science, whether it be in a hospital setting as Radiation Safety Officer, or in the commercial nuclear power industry as an operational Health Physicist. 


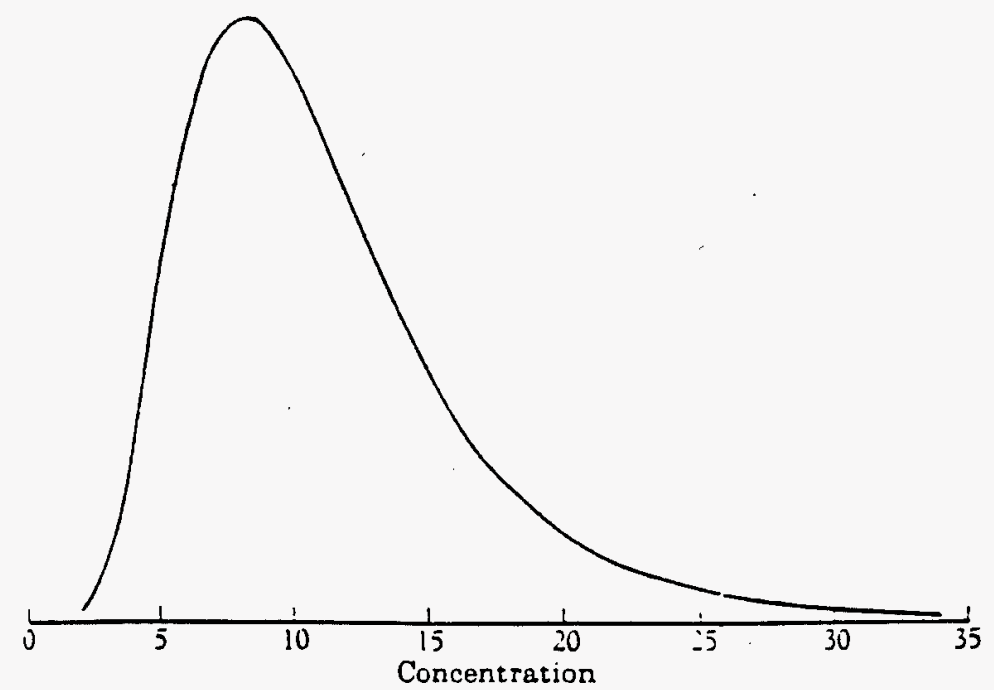

Fxc. 1. Typical distribution curve for the absolute valueg of tolerance concer:tatuons

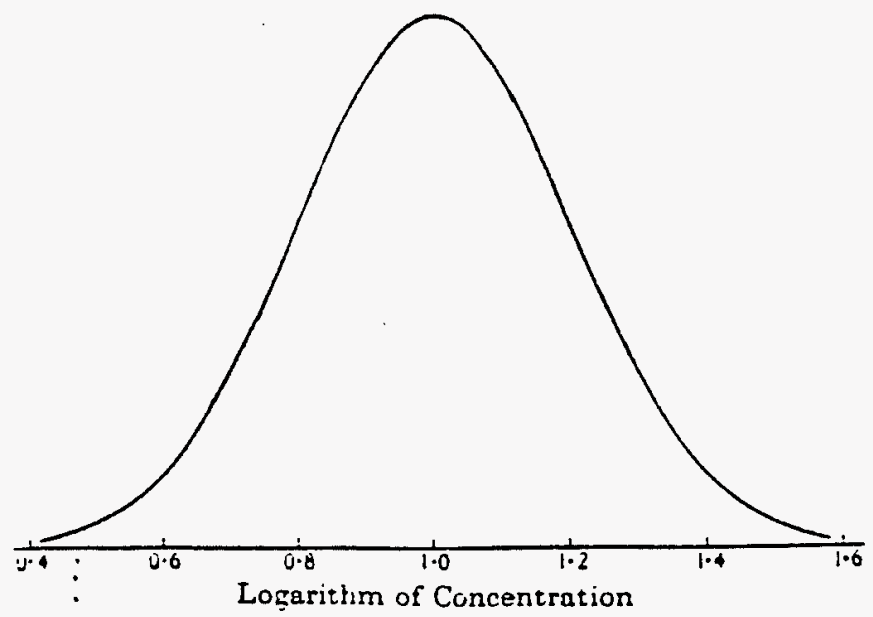

Far. 2. Tormal distribution for tho logarithms of tolerance concentrations, derived from Fig. 1. 


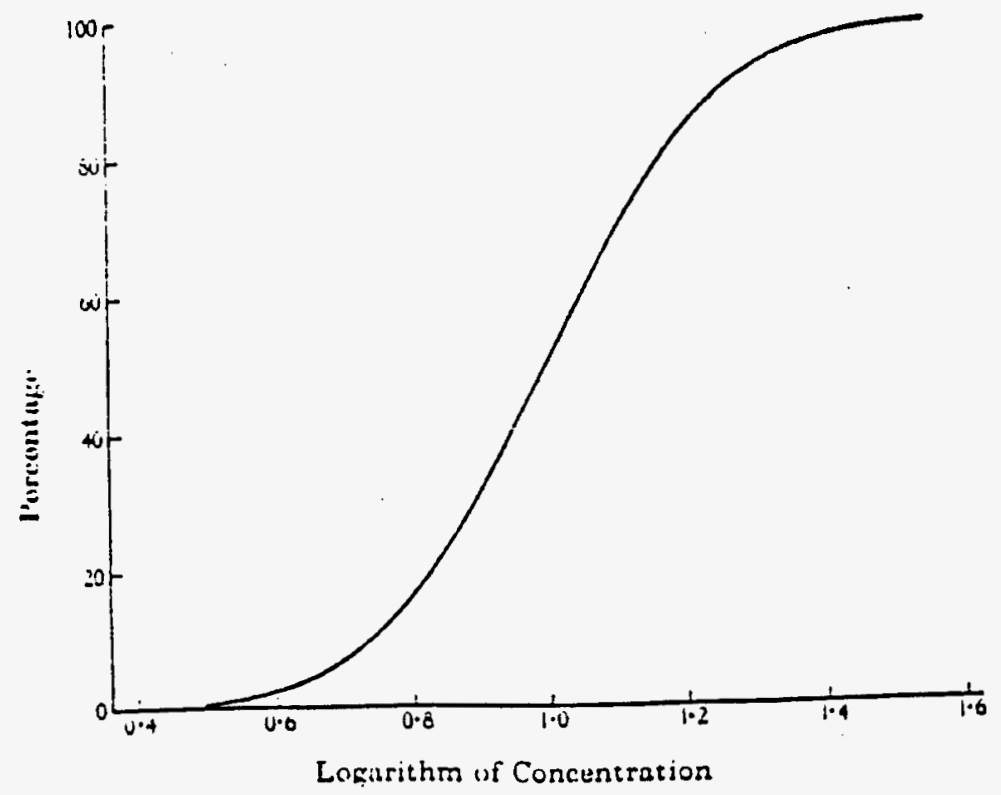

Fig 3. Normul sicmoid curve derived from Fir. : to show percentago whuse lug colerunces are lesis than a specued ralue.

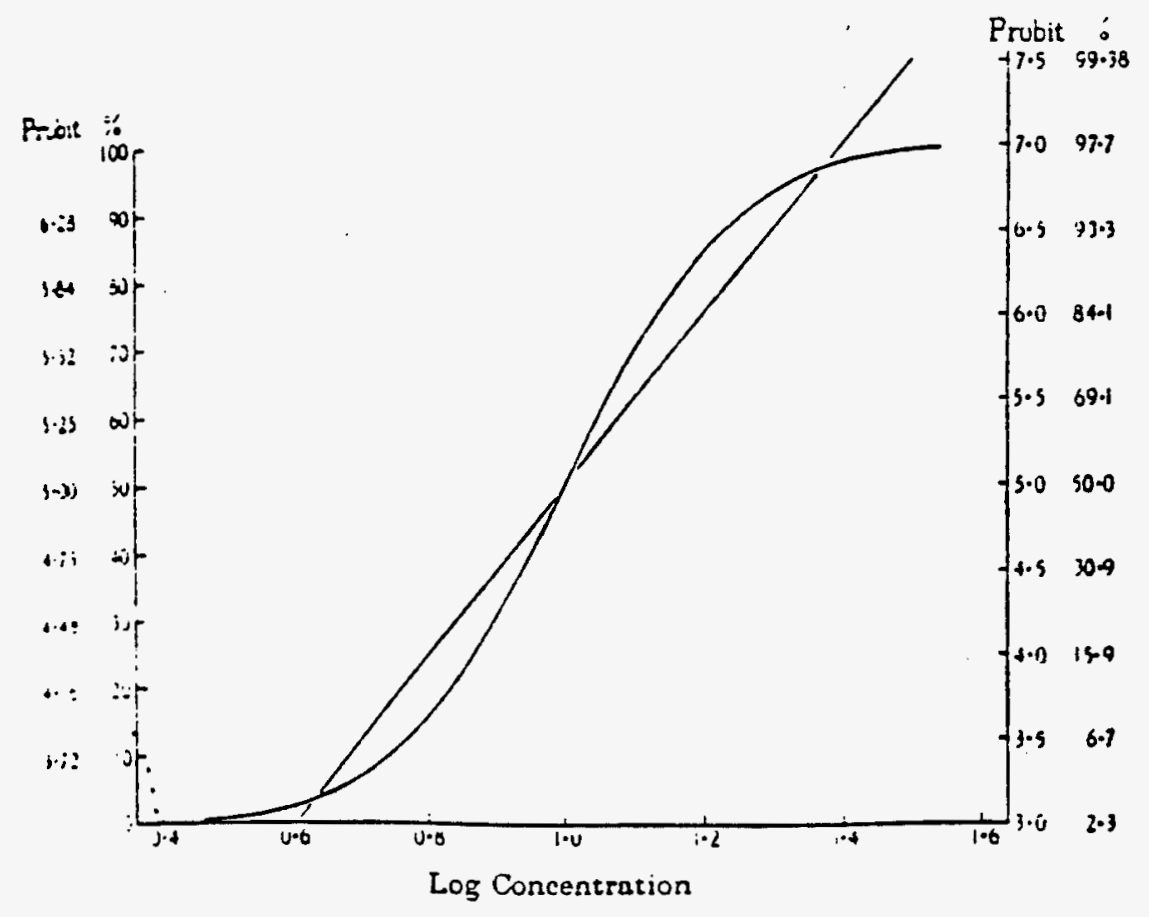

Fig 4. Estect of the probit temsiformution. 
FIGURE 5

RELATIVE DEPTH DOSE DISTRIBUTIONS FOR THREE TYPES OF HOT PARTICLES
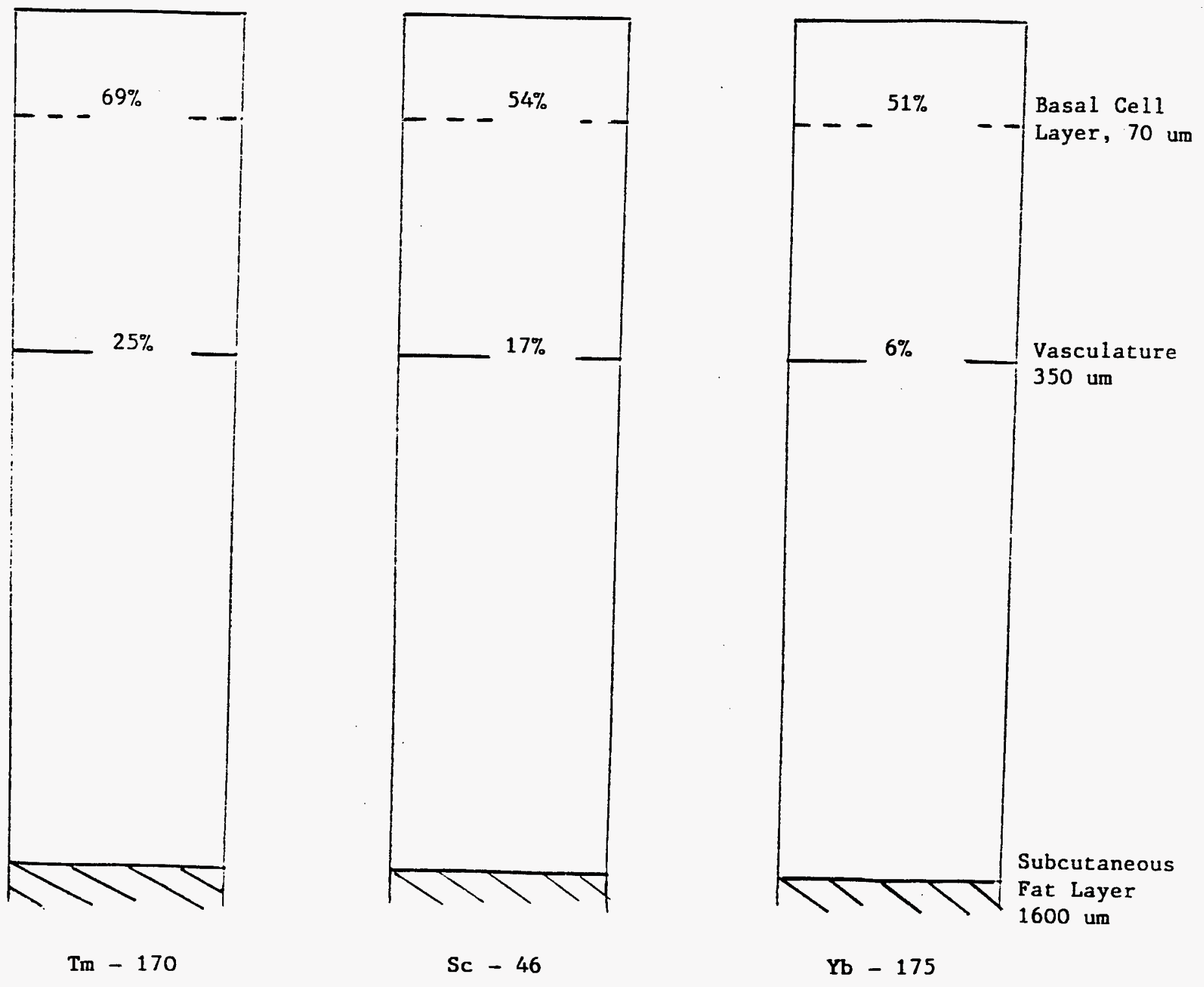

$\operatorname{Tm}-170$

Sc -46

$\mathrm{Yb}-175$ 
FIGURE 6: $10 \%$ DOSES FOR TM-170

SC-46, AND YB-175

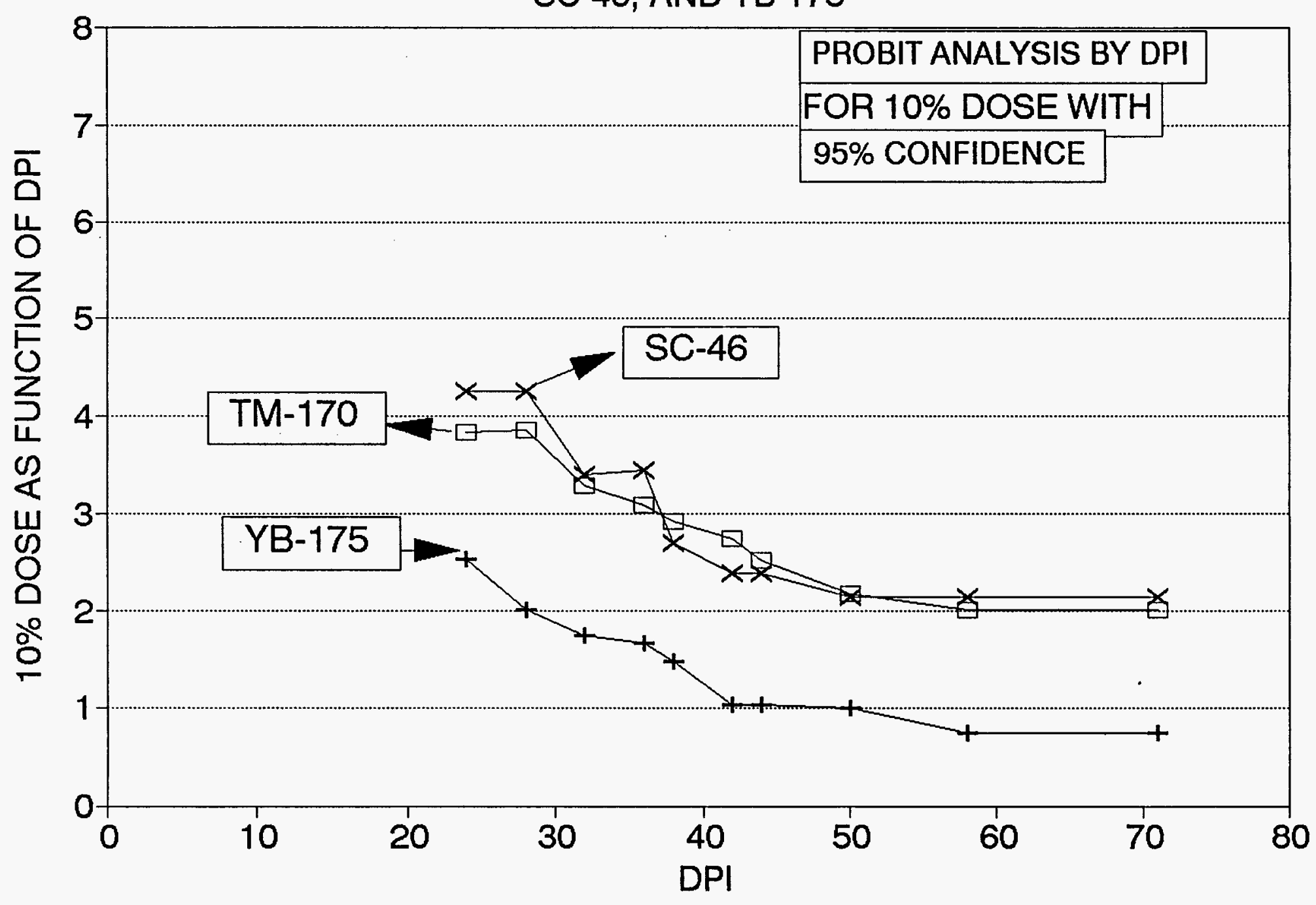




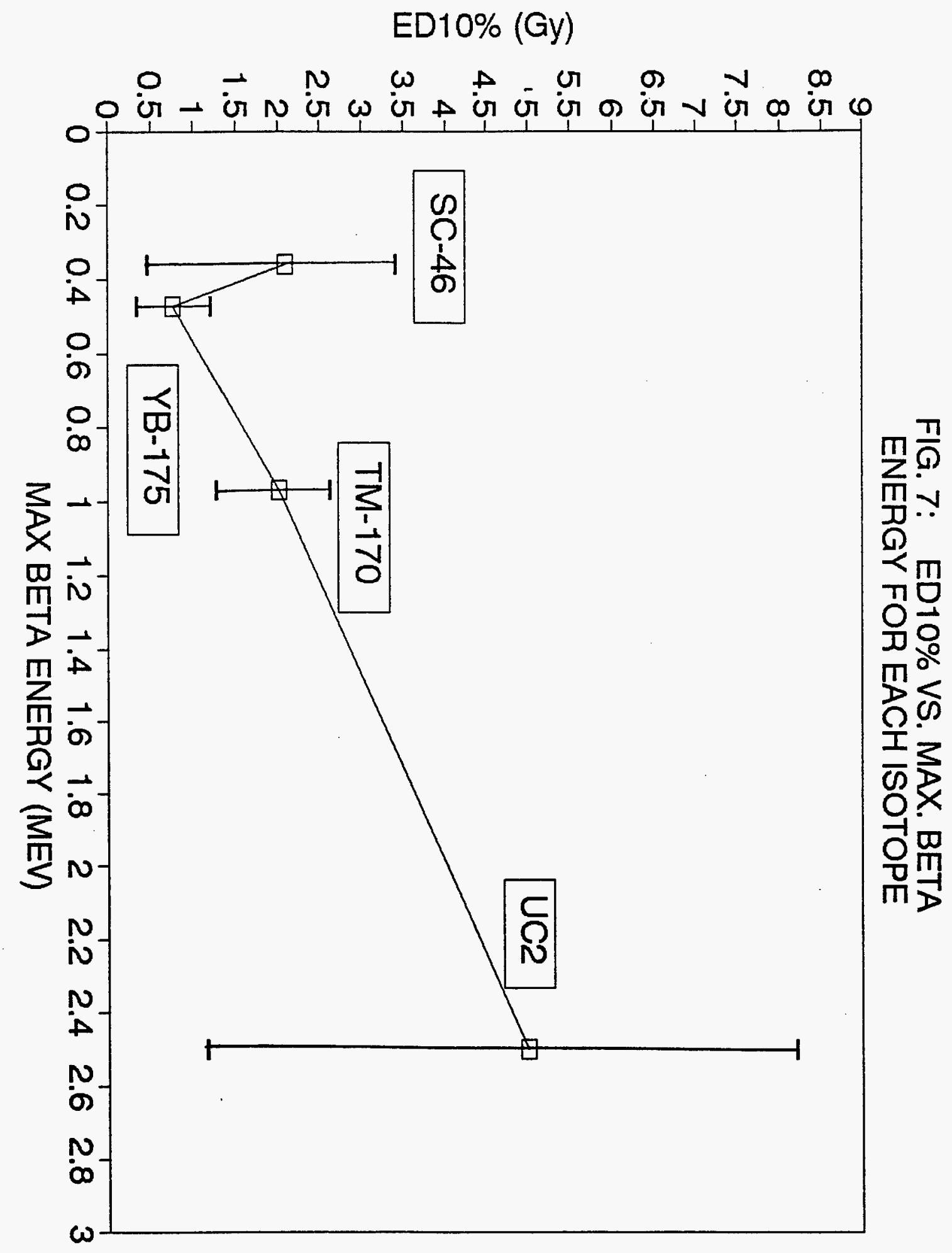


FIGURE 8

SKIN LAYERS AND RELATIVE RANGES OF DIFFERENT ENERGY BETA PARTICLES

EPIDERMIS

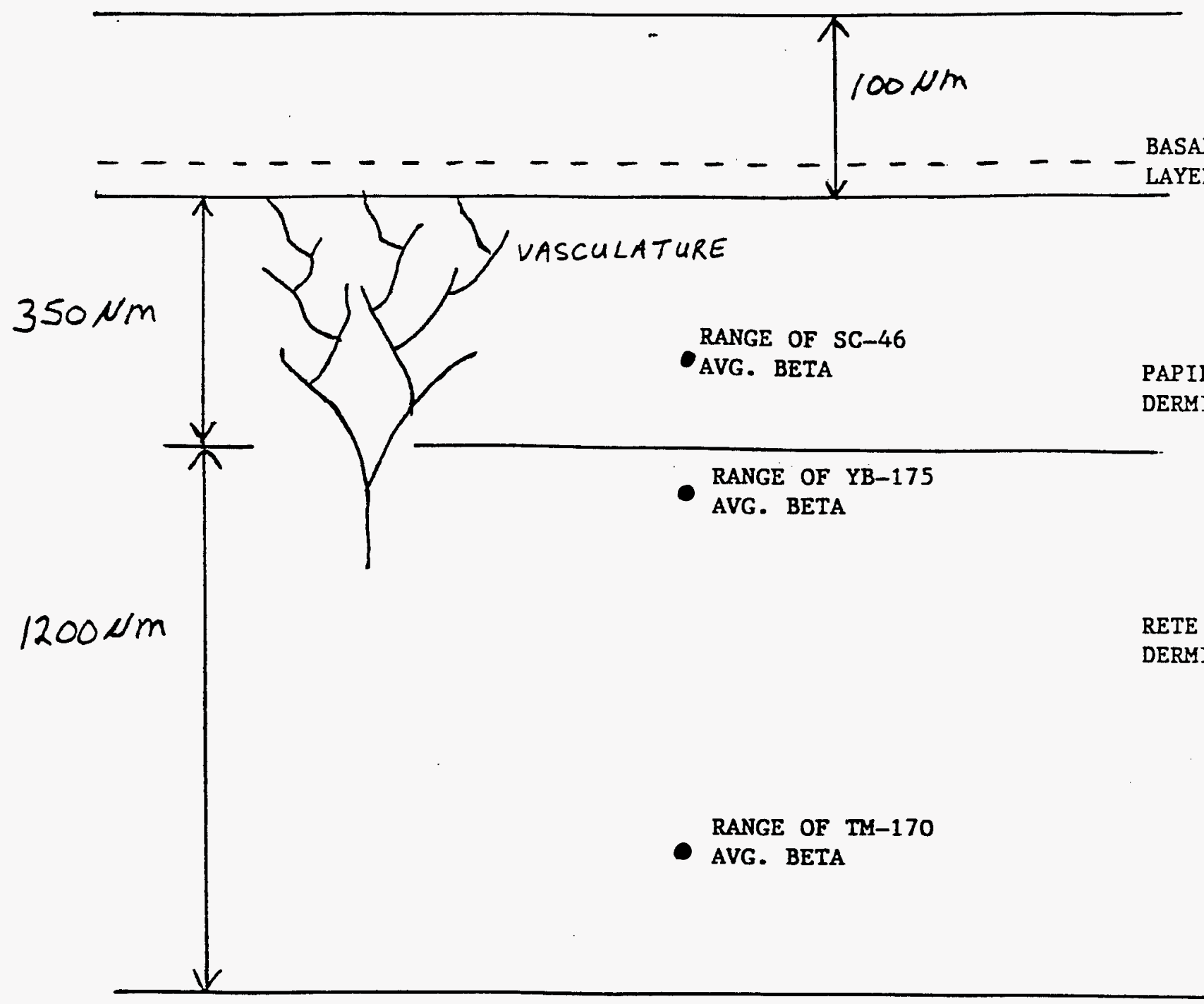

SUBCUTANEOUS

FAT LAYER 
Probability by 3 Cycle Log (Long-axis)

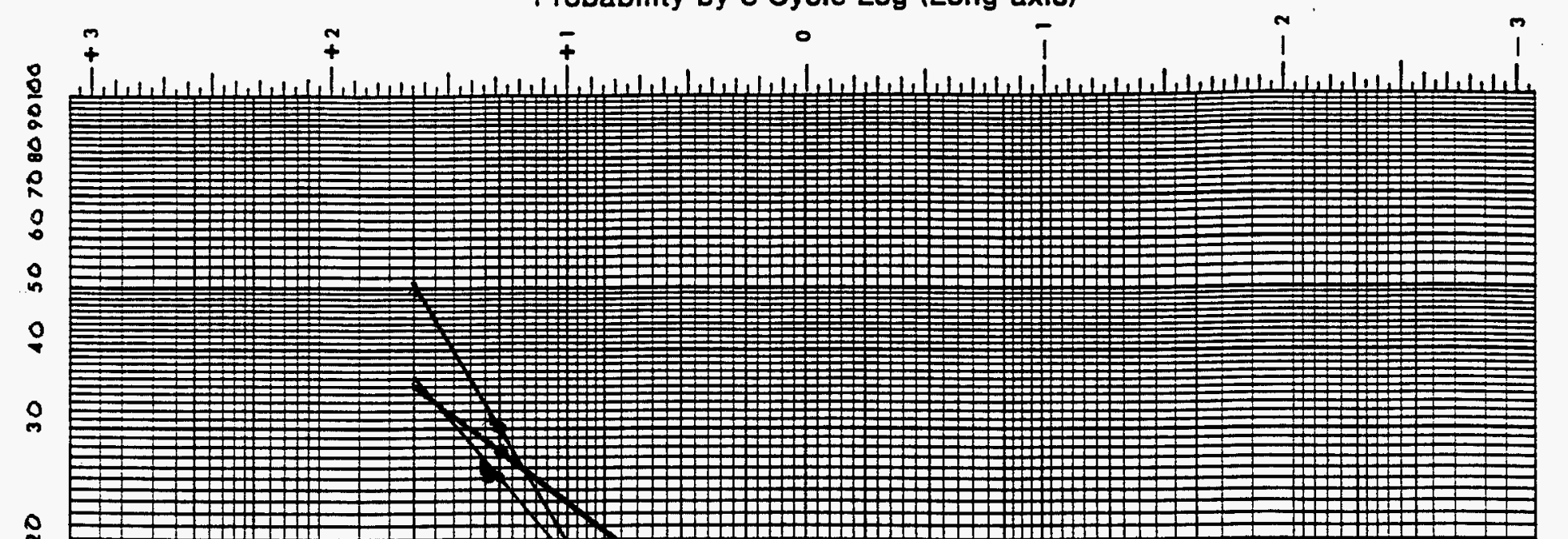

ก

-

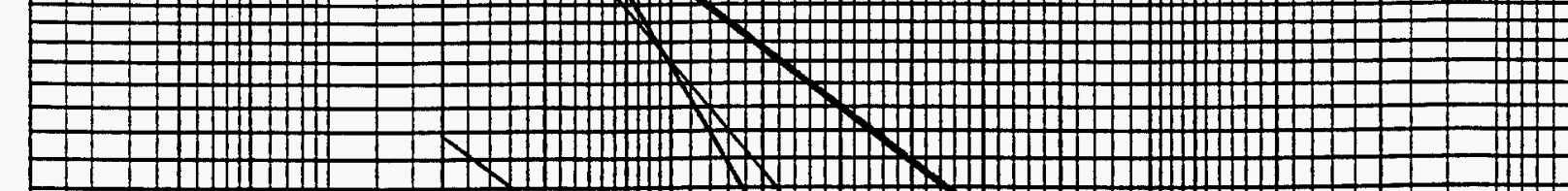

$\underline{0}$
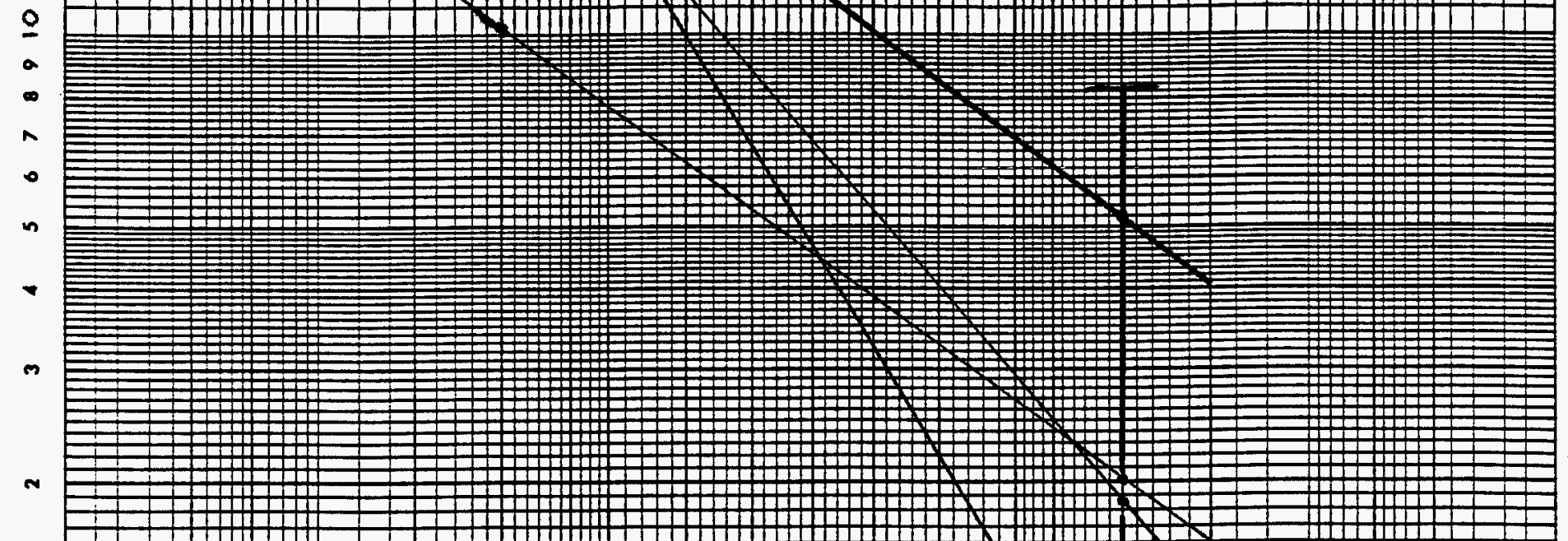
I

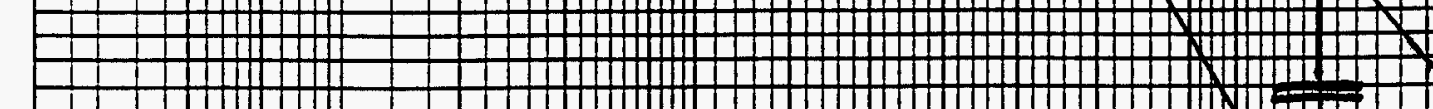

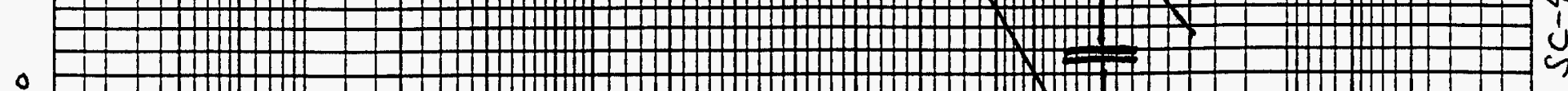

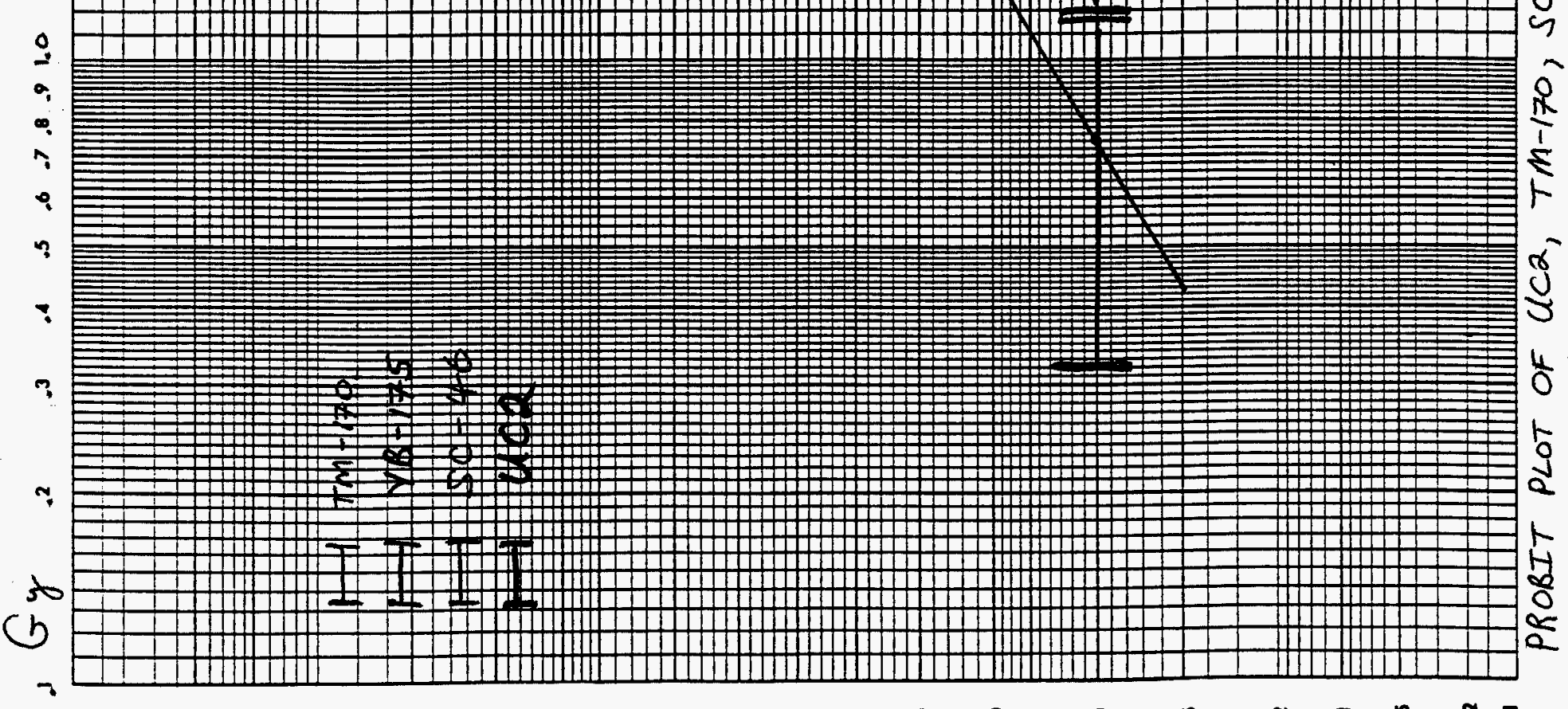

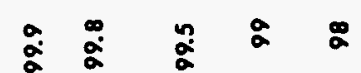
$\approx \quad 2$
$8 \quad 8$
ㅇㅇㅇㅇㅇㅇㅇㅇ
음
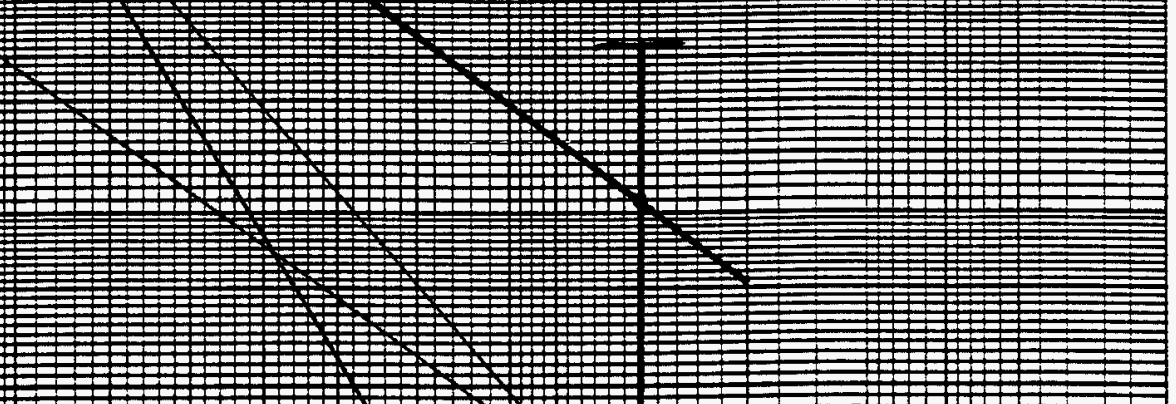

$h$

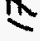

$\infty$

( 
Table 1 SUMMARY OF COMPARISON OF RESULTS FOR DIFFERENT SCORING METHODS FOR TM-170, 10\% DOSE WITH 95\% CONFIDENCE LIMITS (DOSE IN Gy OVER 1 $\mathrm{CM}^{2}, 70$ MICRONS)

\begin{tabular}{|c|c|c|c|c|c|c|}
\hline \multicolumn{4}{|c|}{$28 \mathrm{DPI}$} & \multicolumn{3}{|c|}{$48 \mathrm{DPI}$} \\
\hline SCORING METHOD & $\begin{array}{l}\text { LOWER } \\
\text { BOUND }\end{array}$ & VALUE & $\begin{array}{l}\text { UPPER } \\
\text { BOUND }\end{array}$ & $\begin{array}{l}\text { LOWER } \\
\text { BOUND }\end{array}$ & VALUE & $\begin{array}{l}\text { UPPER } \\
\text { BOUND }\end{array}$ \\
\hline $\begin{array}{l}\text { SEEN 3X IN PERIOD } \\
\text { BY BOTH SCORERS }\end{array}$ & 1.6 & 4.1 & 5.4 & 1.1 & 1.9 & 2.5 \\
\hline $\begin{array}{l}\text { SEEN 3X IN PERIOD } \\
\text { BY } 1 \text { SCORER }\end{array}$ & .97 & 2.2 & 3.2 & 0.02 & 0.49 & 1.20 \\
\hline $\begin{array}{l}\text { SEEN BY BOTH } \\
\text { SCORERS ON } 3 \\
\text { CONSECUTIVE } \\
\text { SCORING DAYS }\end{array}$ & 6.0 & 7.9 & 9.9 & 4.2 & 5.5 & 6.4 \\
\hline $\begin{array}{l}\text { SEEN BY ONE } \\
\text { SCORER ON } 3 \\
\text { CONSECUTIVE } \\
\text { SCORING DAYS }\end{array}$ & N/A & 3.7 & N/A & 1.4 & 2.2 & 2.8 \\
\hline $\begin{array}{l}\text { HOPEWELL'S } \\
\text { METHOD, TWO } \\
\text { SCORERS }\end{array}$ & 3.9 & 5.5 & 6.5 & 2.5 & 3.5 & 4.2 \\
\hline $\begin{array}{l}\text { HOPEWELL'S } \\
\text { METHOD, ONE } \\
\text { SCORER } \\
\end{array}$ & 1.1 & 2.2 & 2.9 & 0.41 & 1.1 & 1.7 \\
\hline C. SCHAEFER & N/A & 3.78 & N/A & 1.43 & 2.18 & 2.78 \\
\hline
\end{tabular}


Table 2 DOSES AND SCAB SIZES FOR PIGS IRRADIATED WITH UC2

PIG \# 156-4

PIG \# 157-2

\begin{tabular}{|c|c|c|c|}
\hline $\begin{array}{l}\text { MAX SCAB } \\
\text { DIAMETER }(\mathrm{mm})\end{array}$ & $\begin{array}{l}70 \mathrm{MICRONS}, 1 \mathrm{CM}^{2} \\
\text { DOSE (Gy) }\end{array}$ & $\begin{array}{l}\text { MAX SCAB } \\
\text { DIAMETER (mm) }\end{array}$ & $\begin{array}{l}70 \text { MCRONS, } 1 \mathrm{CM}^{2} \\
\text { DOSE (Gy) }\end{array}$ \\
\hline 2 & 43.13 & 10 & 470 \\
\hline 2 & 35.34 & 11.5 & 272 \\
\hline 2 & 28.44 & 9 & 183 \\
\hline 1.5 & 22.52 & 8 & 167 \\
\hline 1.5 & 17.72 & 7.5 & 60.8 \\
\hline 2 & 13.8 & 2 & 44.3 \\
\hline 0 & 10.73 & 2 & 28.7 \\
\hline 0 & 8.19 & 5 & 26.6 \\
\hline 1 & 6.26 & 4 & 22 \\
\hline 0 & 4.79 & 0 & 19.5 \\
\hline 0 & 3.66 & 2 & 18.8 \\
\hline 0 & 2.77 & 0 & 14.9 \\
\hline 0 & 2.23 & 1 & 8.5 \\
\hline 0 & 2.21 & 0 & 7.72 \\
\hline 0 & 2.19 & 0 & 6.28 \\
\hline 0 & $2.18(2)$ & & \\
\hline 0 & 2.16 & & \\
\hline 0 & 2.14 & & \\
\hline 0 & 2.13 & & \\
\hline 0 & $2.12(3)$ & & \\
\hline 0 & 1.66 & & \\
\hline 0 & 1.2 & & \\
\hline 0 & $<1.0(2)$ & & \\
\hline
\end{tabular}


Table 3 PROBIT ANALYSIS RESULTS FOR ALL PARTICLE TYPES

\begin{tabular}{|c|c|c|c|c|c|c|c|}
\hline & DOSE RANGE(Gy) & $\mathbf{n}$ & AVG. DOSE & $P(\%)$ & ED10\% & $\begin{array}{l}\text { LOWER } \\
\text { LIMTT }\end{array}$ & $\begin{array}{l}\text { UPPER } \\
\text { LIMTT }\end{array}$ \\
\hline \multirow{4}{*}{$\begin{array}{c}\text { GROUP } \\
\text { A }\end{array}$} & $0-2.5$ & 15 & 2.12 & 0 & \multirow{4}{*}{$4.98 \mathrm{~Gy}$} & \multirow{4}{*}{$0.72 \mathrm{~Gy}$} & \multirow{4}{*}{$8.16 \mathrm{~Gy}$} \\
\hline & $6-13.9$ & 7 & 8.78 & 42.9 & & & \\
\hline & $14-23$ & 6 & 19.25 & 66.7 & & & \\
\hline & $23.1-35.5$ & 5 & 28.3 & 100 & & & \\
\hline \multirow{5}{*}{$\begin{array}{c}\text { GROUP } \\
\text { B }\end{array}$} & $0-5$ & 18 & 2.63 & 0 & \multirow{5}{*}{$5.24 \mathrm{~Gy}$} & \multirow{5}{*}{$1.16 \mathrm{~Gy}$} & \multirow{5}{*}{$8.22 \mathrm{~Gy}$} \\
\hline & $5-10$ & 5 & 7.39 & 40 & & & \\
\hline & $10-15$ & 3 & 13.14 & 33.3 & & & \\
\hline & $15-20$ & 3 & 18.67 & 66.7 & & & \\
\hline & $20-25$ & 2 & 22.26 & 100 & & & \\
\hline
\end{tabular}

\begin{tabular}{|c|c|c|c|}
\hline DPI & $\begin{array}{l}\text { ED10\% } \\
\text { TM-170 }\end{array}$ & $\begin{array}{l}\text { ED10\% } \\
\text { SC-46 }\end{array}$ & $\begin{array}{l}\text { ED10\% } \\
\text { YB-175 }\end{array}$ \\
\hline 24 & $3.83 \mathrm{~Gy}$ & $4.25 \mathrm{~Gy}$ & $2.54 \mathrm{~Gy}$ \\
\hline 28 & $3.85 \mathrm{~Gy}$ & $4.25 \mathrm{~Gy}$ & $2.01 \mathrm{~Gy}$ \\
\hline 32 & $3.29 \mathrm{~Gy}$ & $3.40 \mathrm{~Gy}$ & $1.74 \mathrm{~Gy}$ \\
\hline 36 & $3.09 \mathrm{~Gy}$ & $3.45 \mathrm{~Gy}$ & $1.67 \mathrm{~Gy}$ \\
\hline 38 & $2.93 \mathrm{~Gy}$ & $2.70 \mathrm{~Gy}$ & $1.48 \mathrm{~Gy}$ \\
\hline 42 & $2.73 \mathrm{~Gy}$ & $2.39 \mathrm{~Gy}$ & $1.03 \mathrm{~Gy}$ \\
\hline 44 & $2.52 \mathrm{~Gy}$ & $2.14 \mathrm{~Gy}$ & $1.03 \mathrm{~Gy}$ \\
\hline 50 & $2.18 \mathrm{~Gy}$ & $2.14 \mathrm{~Gy}$ & $1.00 \mathrm{~Gy}$ \\
\hline 58 & $2.02 \mathrm{~Gy}$ & $2.14 \mathrm{~Gy}$ & $0.74 \mathrm{~Gy}$ \\
\hline
\end{tabular}




\begin{tabular}{|c|c|c|c|c|c|}
\hline \multicolumn{6}{|c|}{ PERCENT SCAB INCIDENCE PER DOSE FOR EACH DPI } \\
\hline DAYS & & & & & PROBIT \\
\hline POST & $9.9 \mathrm{~Gy}$ & $7.6 \mathrm{~Gy}$ & $4.7 \mathrm{~Gy}$ & $3.0 \mathrm{~Gy}$ & ANALYSIS \\
\hline IRRAD. & (40 pts.) & (42 pts.) & (42 pts.) & (41 pts.) & ED 10 \\
\hline$======$ & $=====$ & $=====$ & $======$ & $======$ & $======$ \\
\hline 2 & 0 & 0 & 0 & 0 & \\
\hline 4 & 0 & 0 & 0 & 0 & \\
\hline 6 & 0 & 0 & 0 & 0 & \\
\hline 8 & 0 & 0 & 0 & 0 & \\
\hline 10 & 0 & 0 & 0 & 0 & \\
\hline 12 & 0 & 0 & 0 & 0 & \\
\hline 14 & 5.0 & 2.4 & 0.0 & 0.0 & \\
\hline 16 & 20.0 & 4.8 & 7.7 & 0.0 & 7.49 \\
\hline 18 & 25.0 & 4.8 & 9.5 & 7.3 & 5.24 \\
\hline 20 & 32.5 & 14.3 & 9.5 & 7.3 & 4.46 \\
\hline 22 & 55.0 & 21.4 & 11.9 & 9.8 & 3.81 \\
\hline 24 & 57.5 & 21.4 & 11.9 & 9.8 & 3.83 \\
\hline 28 & 60.0 & 21.4 & 11.9 & 9.8 & 3.85 \\
\hline 30 & 75.0 & 35.7 & 23.8 & 9.8 & 3.32 \\
\hline 32 & 75.0 & 40.4 & 23.8 & 9.8 & 3.29 \\
\hline 36 & 82.5 & 52.4 & 26.2 & 12.2 & 3.09 \\
\hline 38 & 82.5 & 57.1 & 26.2 & 14.6 & 2.93 \\
\hline 40 & 82.5 & 61.9 & 31.0 & 14.6 & 2.81 \\
\hline 42 & 87.5 & 69.0 & 38.1 & 14.6 & 2.73 \\
\hline 44 & 90.0 & 71.4 & 45.2 & 17.1 & 2.52 \\
\hline 50 & 95.0 & 71.4 & 45.2 & 26.8 & 2.18 \\
\hline 58 & 95.0 & 73.8 & 50.0 & 29.3 & 2.02 \\
\hline 71 & 95.0 & 73.8 & 50.0 & 29.3 & 2.02 \\
\hline
\end{tabular}


TABLE 5.

SC-46 DATA TABLE

DOSE 70uM, 1CM^2

\begin{tabular}{|c|c|c|c|c|c|c|}
\hline DAYS & & & 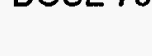 & . & & PROBIT \\
\hline POST & 53 Gy & $17.5 \mathrm{~Gy}$ & $8.8 \mathrm{~Gy}$ & $4.4 \mathrm{~Gy}$ & 2(2.2) Gy & ANALYSIS \\
\hline IRRAD. & (4 pts.) & (5 pts.) & (8 pts.) & (12 pts.) & (10 pts.) & ED 10 \\
\hline$====\quad$ & $====$ & $=====$ & $====$ & $====$ & $=====$ & $====$ \\
\hline 3 & 0.0 & 0.0 & 0.0 & 0.0 & 0.0 & \\
\hline 5 & 0.0 & 0.0 & 0.0 & 0.0 & 0.0 & \\
\hline 8 & 0.0 & 0.0 & 0.0 & 0.0 & 0.0 & \\
\hline 10 & 0.0 & 0.0 & 0.0 & 0.0 & 0.0 & \\
\hline 12 & 50.0 & 0.0 & 0.0 & 0.0 & 0.0 & \\
\hline 15 & 50.0 & 0.0 & 0.0 & 0.0 & 0.0 & \\
\hline 17 & 50.0 & 0.0 & 0.0 & 0.0 & 0.0 & \\
\hline 19 & 50.0 & 0.0 & 0.0 & 0.0 & 0.0 & \\
\hline 22 & 75.0 & 40.0 & 12.5 & 0.0 & 0.0 & \\
\hline 24 & 75.0 & 60.0 & 25.0 & 8.3 & 0.0 & 4.25 \\
\hline 25 & 100.0 & 60.0 & 25.0 & 8.3 & 0.0 & 4.25 \\
\hline
\end{tabular}

DUE TO BIOPSIES ON 8/23/94, THE NUMBER OF POINTS AT 8 Gy HAVE BEEN REDUCED FROM 8 TO 6.

$\begin{array}{rrrrrrl}29 & 100.0 & 60.0 & 33.0 & 8.3 & 0.0 & 4.25 \\ 32 & 100.0 & 60.0 & 33.0 & 8.3 & 10.0 & 3.40 \\ 36 & 100.0 & 80.0 & 33.0 & 8.3 & 10.0 & 3.45 \\ 39 & 100.0 & 80.0 & 33.0 & 25.0 & 10.0 & 2.70 \\ 42 & 100.0 & 80.0 & 33.0 & 33.0 & 10.0 & 2.39 \\ 46 & 100.0 & 100.0 & 50.0 & 41.7 & 10.0 & 2.14 \\ 50 & 100.0 & 100.0 & 50.0 & 41.7 & 10.0 & 2.14 \\ 53 & 100.0 & 100.0 & 50.0 & 41.7 & 10.0 & 2.14 \\ 57 & 100.0 & 100.0 & 50.0 & 41.7 & 10.0 & 2.14 \\ 71 & 100.0 & 100.0 & 50.0 & 41.7 & 10.0 & 2.14\end{array}$


TABLE 6.

YB-175 DATA TABLE

PERCENT SCAB INCIDENCE PER DOSE FOR EACH DPI

\begin{tabular}{|c|c|c|c|c|c|c|}
\hline & DOSE AT 7 & $\mathrm{UM}, 1 \mathrm{CM}^{\prime}$ & & & & \\
\hline DAYS & & & & & & \\
\hline $\begin{array}{l}\text { POST } \\
\text { IRRAD. }\end{array}$ & $\begin{array}{c}14.9 \mathrm{~Gy} \\
\text { (10 pts.) }\end{array}$ & $\begin{array}{l}7.6 \mathrm{~Gy} \\
\text { (3 pts.) }\end{array}$ & $\begin{array}{c}2.4 \mathrm{~Gy} \\
\text { (15 pts.) }\end{array}$ & $\begin{array}{c}1.2 \mathrm{~Gy} \\
\text { (20 pts.) }\end{array}$ & $\begin{array}{c}0.62 \mathrm{~Gy} \\
\text { (28 pts.) }\end{array}$ & $\begin{array}{l}0.31 \mathrm{~Gy} \\
\text { (28 pts.) }\end{array}$ \\
\hline$====$ & $=====$ & $=====$ & $======$ & $=====$ & $=====$ & $======$ \\
\hline 2 & 0.0 & 0.0 & 0.0 & 0.0 & 0.0 & 0.0 \\
\hline 3 & 0.0 & 0.0 & 0.0 & 0.0 & 0.0 & 0.0 \\
\hline 4 & 0.0 & 0.0 & 0.0 & 0.0 & 0.0 & 0.0 \\
\hline 6 & 0.0 & 0.0 & 0.0 & 0.0 & 0.0 & 0.0 \\
\hline 7 & 0.0 & 0.0 & 0.0 & 0.0 & 0.0 & 0.0 \\
\hline 8 & 0.0 & 0.0 & 0.0 & 0.0 & 0.0 & 0.0 \\
\hline 9 & 0.0 & 0.0 & 0.0 & 0.0 & 0.0 & 0.0 \\
\hline 10 & 0.0 & 0.0 & 0.0 & 0.0 & 0.0 & 0.0 \\
\hline 11 & 0.0 & 0.0 & 0.0 & 0.0 & 0.0 & 0.0 \\
\hline 13 & 0.0 & 0.0 & 0.0 & 0.0 & 0.0 & 0.0 \\
\hline 14 & 10.0 & 0.0 & 0.0 & 0.0 & 0.0 & 0.0 \\
\hline 15 & 20.0 & 0.0 & 0.0 & 0.0 & 0.0 & 0.0 \\
\hline 16 & 20.0 & 0.0 & 0.0 & 0.0 & 0.0 & 0.0 \\
\hline 17 & 20.0 & 0.0 & 0.0 & 0.0 & 0.0 & 0.0 \\
\hline 18 & 20.0 & 0.0 & 0.0 & 0.0 & 0.0 & 0.0 \\
\hline 20 & 20.0 & 0.0 & 0.0 & 0.0 & 0.0 & 0.0 \\
\hline 21 & 30.0 & 0.0 & 6.7 & 0.0 & 0.0 & 0.0 \\
\hline 22 & 30.0 & 0.0 & 13.3 & 0.0 & 0.0 & 0.0 \\
\hline 23 & 30.0 & 33.3 & 13.3 & 0.0 & 0.0 & 0.0 \\
\hline
\end{tabular}

Actual

Probit

Analysis

ED10 value

$==ニ=ニ=$

DUE TO BIOPSIES BEING TAKEN ON 8/19, THE NUMBER OF POINTS AT

9.6 AND 8 Gy HAVE BEEN REDUCED TO 8 AND 18 RESPECTIVELY.

$\begin{array}{llllllll}24 & 37.5 & 33.3 & 13.3 & 5.6 & 0.0 & 0.0 & 2.54 \\ 28 & 37.5 & 33.0 & 13.3 & 11.1 & 0.0 & 0.0 & 2.01 \\ 31 & 62.5 & 33.0 & 13.3 & 11.1 & 0.0 & 0.0 & 1.74 \\ 34 & 75.0 & 33.0 & 13.3 & 11.1 & 0.0 & 0.0 & 1.67 \\ 37 & 87.5 & 33.0 & 20.0 & 11.1 & 0.0 & 0.0 & 1.48 \\ 41 & 87.5 & 33.0 & 20.0 & 11.1 & 3.6 & 3.6 & 1.03 \\ 45 & 87.5 & 33.0 & 20.0 & 11.1 & 3.6 & 3.6 & 1.03 \\ 49 & 87.5 & 33.0 & 20.0 & 16.7 & 3.6 & 3.6 & 1.00 \\ 52 & 87.5 & 33.0 & 26.7 & 16.7 & 3.6 & 7.1 & 0.74 \\ 55 & 87.5 & 33.0 & 26.7 & 16.7 & 3.6 & 7.1 & 0.74 \\ 71 & 87.5 & 33.0 & 26.7 & 16.7 & 3.6 & 7.1 & 0.74\end{array}$


M97053788

Report Number (14) DOE/OR/00033- T756

Publ. Date (11) 199411

Sponsor Code (18) DOE $/ E+1, X F$

UC Category (19) $4 C-600, D O E / E R$

DOE 